\title{
Combining inhibition of galectin-3 with and before a therapeutic vaccination is critical for the prostate-tumor- free outcome
}

\author{
Carolina Tiraboschi, ${ }^{1}$ Lucas Gentilini, ${ }^{1}$ Carla Velazquez, ${ }^{1}$ Enrique Corapi, ${ }^{1}$ \\ Felipe Martín Jaworski, ${ }^{1}$ José Daniel Garcia Garcia, ${ }^{1}$ Yorfer Rondón, ${ }^{1}$ \\ Anne Chauchereau, ${ }^{2}$ Diego José Laderach, ${ }^{1,3}$ Daniel Compagno (D) ${ }^{1}$
}

To cite: Tiraboschi C, Gentilini L, Velazquez C, et al. Combining inhibition of galectin-3 with and before a therapeutic vaccination is critical for the prostatetumor-free outcome. Journal for ImmunoTherapy of Cancer 2020;8:e001535. doi:10.1136/ jitc-2020-001535

- Additional material is published online only. To view please visit the journal online (http://dx.doi.org/10.1136/jitc2020-001535).

Accepted 18 November 2020

Check for updates

(C) Author(s) (or their employer(s)) 2020. Re-use permitted under CC BY-NC. No commercial re-use. See rights and permissions. Published by BMJ.

${ }^{1}$ Quimica biologica, IQUIBICENCONICET-UBA, Ciudad Autonoma de Buenos Aires, Argentina

${ }^{2}$ U981, INSERM, Paris, Île-deFrance, France

${ }^{3}$ Universidad Nacional de Lujan, Lujan, Argentina

\section{Correspondence to}

Dr Daniel Compagno, Quimica Biologica, IQUIBICEN-CONICETUNA, Cuidad Autonoma de Buenos Aires, CABA, Argentina; danielcompagno@gmail.com

\section{ABSTRACT}

Background Prostate cancer $(\mathrm{PCa})$ is a major health problem worldwide. Taxol derivatives-based chemotherapies or immunotherapies are usually proposed depending on the symptomatic status of the patient. In the case of immunotherapy, tumors develop robust immune escape mechanisms that abolish any protective response, and to date why prostate cancer is one of the most resistant diseases remains unresolved.

Methods By using a combination of clinical data to study the transcriptome of metastasis samples from patients with castration-refractory prostate cancer, and state of the art cellular and molecular biology assays in samples from tumor-bearing mice that have been submitted to surgical resection of the tumor before receiving a vaccination, we answered several essential questions in the field of immunotherapy for prostate cancer. We also used two different methods to inhibit the expression of galectin-3 (Gal-3) in tumor cells: a stable RNA interference method to control the expression of this galectin efficiently only in tumor cells, and low and non-cytotoxic doses of docetaxel to easily transfer our findings to clinical settings.

Results Herein, we show for the first time that Gal-3 expressed by prostate tumor cells is the main immune checkpoint responsible for the failure of vaccine-based immunotherapy. Our results show that low and noncytotoxic doses of docetaxel lead to the inhibition of Gal-3 expression in PCa cells as well as in clinical samples of patients with metastatic and castration-resistant PCa promoting a Th1 response. We thus optimized a prostate cancer animal model that undergoes surgical resection of the tumor to mimic prostatectomy usually performed in patients. Importantly, using Gal-3-knocked down-PCa cells or low and non-cytotoxic doses of taxane before vaccination, we were able to highly control tumor recurrence through a direct impact on the proliferation and infiltration of CD8+ cytotoxic T.

Conclusions Thus, Gal-3 expression by PCa cells is a crucial inhibitor for the success of immunotherapy, and low doses of docetaxel with non-cytotoxic effect on leukocyte survival could be used before immunotherapy for all patients with PCa to reduce the expression of this critical negative immune checkpoint, pre-conditioning the tumor-microenvironment to activate an antitumor immune response and promote tumor-free outcome.

\section{BACKGROUND}

Prostate cancer (PCa) is responsible for suffering and death worldwide (International Agency for Research on Cancer, WHO). ${ }^{1}$ Early diagnosis and rapid treatment play critical roles in patient outcome. While initial phases with localized and castration-sensitive PCa are curable, those with metastatic and castration-resistant PCa (mCRPC) are not. At this stage, the primary treatment option for symptomatic patients is chemotherapy with Taxol-derived molecules such as docetaxel. However, $50 \%$ of the patients develop chemotherapy resistance, and few other therapeutics are available. ${ }^{2}$ It is, therefore, essential to evaluate alternative approaches to prevent tumor spreading and progression to advanced stages of this disease. In this scenario, immunotherapy represents an exciting option to induce an antitumor response by targeting the patient's immune system directly. ${ }^{3}$

Immunotherapy is an attractive therapeutic strategy for PCa since the immune system does not ignore tumor cells, as evidenced by the presence of lymphocyte infiltration in prostate tumors. ${ }^{4}$ These infiltrates are also characterized by high levels of regulatory $\mathrm{T}$ cells (TReg). ${ }^{5-7}$ Recent clinical data provide clear evidence of antigenic determinants expressed in various types of human tumors that could be targeted by autologous $\mathrm{T}$ cells, and optimization of such reactivity could lead to cancer regression. ${ }^{8-10}$ Sipuleucel-T, the first Food and Drug Administration (FDA)approved antigen-specific immunotherapy for cancer treatment, is a personalized vaccine based on autologous dendritic cells (DC) that are supposed to activate PAP-specific CD4+ and CD8+ $\mathrm{T}$ cells in treated patients with PCa. ${ }^{11}$ Sipuleucel-T is only used for asymptomatic patients with mCRPC and induces 
a 4.1-month improvement in median survival. Furthermore, analysis of the 3-year survival rate demonstrated an $8.7 \%$ improvement in patients treated with Sipuleucel-T compared with the placebo group but without adequate control of disease progression. ${ }^{12}$

In contrast, GVAX, an allogenic PCa tumor vaccine, failed to demonstrate overall efficiency when compared with docetaxel as the reference therapy. Altogether, the low efficiency of immunotherapies ${ }^{13}$ demonstrates that prostate tumor cells create a particular microenvironment to evade immune attacks. In this respect, encouraging results have been obtained in clinical trials based on over-riding $\mathrm{T}$ cell tolerance. ${ }^{14-18}$

During the last decade, the scientific community demonstrated the involvement of protein-glycan interactions in shaping a tumor-associated immune-suppressive microenvironment ${ }^{19}$ through multiple mechanisms. ${ }^{20-27}$ While these functions of glycans seem unequivocally described and proven in several experimental settings, the recognition of the glycophenotype by lectins, in particular galectins (Gals), is likely an essential means of tumor-immune tolerance. Interestingly, Gals have been implicated in several situations of immune regulation, with major roles in shaping $\mathrm{T}$ cell function in different experimental settings and promoting tumor immune tolerance. ${ }^{28}$ In particular, much attention has been focused on galectin-1 (Gal-1), a member of this family with higher expression levels in PCa and the only galectin whose expression is upregulated during disease progression. Gal-1 seems to have a significant effect on neovascularization in $\mathrm{PCa} .{ }^{29}$

In contrast, the downregulation of full-length Gal-3 observed in patients matches neither with the definition of Gal-3 as a marker of PCa tumor cell aggressiveness nor with a poor prognosis marker for patients with PCa that were previously demonstrated. ${ }^{30-32}$ Gal-3 is ubiquitously expressed in various mammalian tissues, localized both in cytoplasm and nuclei ${ }^{33}$ and able to be secreted to the extracellular medium, where it interacts with many glycoproteins and glycolipids in the cell membrane. In the nuclei, it has been proven to participate in the modulation of cell survival, DNA damage response, ${ }^{34}$ and messenger RNA splicing. ${ }^{35}{ }^{36}$ It has also been shown to participate in numerous molecular pathways related to the development of cancers, such as activation of the K-ras/MEK pathway ${ }^{37}$ and the Wnt, Notch, and EGFR/ FGFR pathways, closely related to cancer stemness. ${ }^{38}$ However, because Gal-3 controls the functions of a variety of antitumor immune cells, ${ }^{28}{ }^{39-44}$ we decided to further investigate its role in antitumor immune responses. To rapidly transfer our results to clinics, we paid special attention to conditions where a chemotherapy treatment is associated with vaccination since results from clinical trials have shown that docetaxel-based chemotherapy could promote the effectiveness of immunotherapy in a variety of cancers ${ }^{45-50}$ as well as in patients with PCa. ${ }^{51} 52$ To date, the mechanism of this synergic effect of the combinatory therapy protocol remains unclear. Altogether, these clinical results reveal that much needs to be understood to improve the efficiency of immunotherapy in PCa.

Herein, our results highlight that prostate tumors recover high expression of Gal-3 at metastatic stages of the disease, and that Gal-3 expressed by PCa cells is the main negative checkpoint responsible for the immunotherapy failure in patients. We also show that treatment with low and non-toxic doses of docetaxel (LDD) highly downregulates this new negative immune checkpoint. Finally, we propose a simple immunotherapy protocol in which a treatment of PCa cell lines or mice-bearing tumors with LDD right after primary tumor resection and before immunotherapy promotes the effectiveness of an anti-PCa therapeutic vaccine through the preconditioning downregulation of tumor-expressing Gal-3. Such a strategy allows the activation and expansion of antitumor CD8+ cytotoxic T cells to control tumor recurrence effectively. These findings could be rapidly transferred to clinical protocols for all patients with PCa.

\section{MATERIALS AND METHODS \\ Cells and animals}

Murine PCa cell line TRAMP-C1 (TC1; obtained from ATCC in 2009) was cultured in Dulbecco's Modified Eagle Medium (DMEM; Invitrogen), 10\% heatinactivated fetal bovine serum (FBS) (Gibco), antibiotics (penicillin $1 \mathrm{U} / \mathrm{mL}$, streptomycin $1 \mu \mathrm{g} / \mathrm{mL}$, amphotericin $2.5 \mathrm{ng} / \mathrm{mL})$ and insulin $(5 \mu \mathrm{g} / \mathrm{mL})$. Cell morphology was routinely evaluated, and cells were periodically examined for androgen sensitivity (MTT assay) and mycoplasma contamination (PCR and DAPI staining followed by fluorescent microscopy). For the in vivo assays, 6-week-old male wild-type C57BL/6 mice were obtained from FCEyN-UBA (Buenos Aires, Argentina), 6-week-old nude Foxn $1^{\text {nu }}$ C57BL/6 mice were obtained from The National University of La Plata (La Plata, Argentina) and maintained in accordance with the Institutional Animal Care and Use Committee guidelines (IAUCC protocol \#2016-038, FCEyN, Buenos Aires, Argentina) and Animal procedures complied with the Guidelines for the Welfare of Animals in Experimental neoplasia (UK). Docetaxel treatment $(0.83 \mathrm{mg} / \mathrm{kg} /$ mouse: a LDD did not present cytotoxic activity neither against TC1 tumor growth nor lymph node or blood cell viability (data not shown)) was performed for 2 weeks and once a week by intraperitoneal (IP) injections.

\section{Lentivirus vector production and transduction of cells}

Lentivirus production and transduction of TC1 cells were performed as previously described. ${ }^{29}$ After 1 week, transduced cells $(\mathrm{GFP}+)$ were purified by cell sorting using a FACSAria II cytometer (BD Bioscience). Purification of the transduced cells was carried out if GFP+ cells did not exceed $20 \%$, in order to minimize the number of viral integrations and thus guarantee a minimum perturbation of the genome. 


\section{Real-time RT-PCR}

Transcriptional profile of galectins was analyzed in all cell lines at log phase of growth. RNA purification, reverse transcription reaction, quantitative PCR conditions and data analysis were performed as previously described. ${ }^{29}$ $36 \mathrm{~B} 4$ was used as an internal reference gene. ${ }^{53}$ Primers sequences are listed in. ${ }^{29}$ Equivalent amounts of RNA were tested to rule out residual genomic DNA contamination.

\section{High-throughput cDNA analysis of mCRPC clinical samples}

We browsed the clinical sample data from. ${ }^{54}$ These data were obtained from a cohort of patients with PCa at a different stage of the disease. We selected 35 patients with mCRPC to study their gene expression profiles, including three untreated patients with mCRPC as the reference population, and 32 patients treated with taxane-based chemotherapy. Gene expression levels were calculated as the relative expression of an individual gene to the gene's expression level in a reference population. The study approval and patients consent were included in the original publication. ${ }^{54}$

\section{Immunoblotting, immunohistochemistry, and flow cytometry analysis}

Immunoblotting and immunohistochemistry and flow cytometry analysis were performed as previously described, ${ }^{29} 55$ and primary antibodies are listed in online supplemental table 3 .

\section{Cell growth analysis}

Cell growth was determined by numbering viable cells at regular intervals of time. Initially, 5000 cells were seeded in 96-well plates in complete culture medium in triplicate for each culture condition. Treatment with indicated doses of docetaxel (kindly gift from Roffo hospital, CABA, Argentina) was performed on day 1 post-cell plating. The cells were trypsinized on day 3 post-treatment and counted in a Neubauer chamber in the presence of trypan blue to discriminate viable from dead cells.

\section{Tumor growth analysis}

TC1-shCtrl or TC1-shGal-3 $\left(2 \times 10^{6}\right.$ tumor cells/mouse in $50 \%$ v/v Matrigel, BD Biosciences) were subcutaneously injected into 6 to 8 week-old male wild-type or Foxn $1^{\text {nu }}$ nude mice in the right flank and measured as previously described.$^{53}$ When the tumor reached an approximate volume of $1.5 \mathrm{~cm}^{3}$, animals were sacrificed and tumors were fixed with $4 \%$ formaldehyde in phosphate-buffered saline (PBS) and then paraffin sections ( $5 \mu \mathrm{m}$ thick) were processed and stained with modified Masson trichrome (MT) or immunostained. Otherwise, tumors were resected by surgery before vaccination/docetaxel treatment ( $\mathrm{n}$ are indicated in corresponding tables).

\section{TIL analysis and in vivo Matrigel plug assay}

In this case, $2 \times 10^{6} \mathrm{TC} 1$ cells in $500 \mu \mathrm{l}$ of Matrigel (4:5) were subcutaneously injected into 6 to 8 week-old C57BL/6 mice (day 7) following vaccination (day 0) and docetaxel treatment $(0.83 \mathrm{mg} / \mathrm{kg}$ by IP injection on day 10) $(n=4)$. On day 12, Matrigel plugs were harvested and mechanically disrupted in $1.5 \mathrm{~mL}$ Eppendorf tubes in the presence of trypsin to study the tumor-infiltrating lymphocytes (TIL). Subsequently, cells were centrifuged at low speed (200 rpm for $1 \mathrm{~min}$ ) and the supernatant containing the recovered cells was stored, discarding the non-disaggregated plug fragments (pellet). From supernatant, the lymphoid cell number was determined in the Neubauer chamber in the presence of trypan blue. The Plug infiltrating cells were then phenotyped by flow cytometry for the expression of surface molecules (CD8, CD4, CD69, CD122, and CD25) and for intracellular expression of FoxP3 as previously described. ${ }^{55}$

\section{Vaccine based on autologous bone-marrow-derived dendritic} cells

Preparation of BM-DC is adapted from published protocols. ${ }^{56}$ Briefly, the development of dendritic cells (DC) from murine bone marrow (BM) progenitor cells was performed as previously published. ${ }^{56} \mathrm{BM}$ cells were cultured overnight in DMEM (Life Technologies) with $10 \%$ FCS (fetal calf serum), $1 \%$ penicillin, streptomycin, and amphotericin in a Petri dish. On day 1 , cells were cultured with murine IL4 $(500 \mathrm{U} / \mathrm{mL}$; ) and murine GM-CSF (20 ng/mL; both cytokine from ImmunoTools) for 5 days. Non-adherent cells were then re-plated at $1 \times 10^{5}$ cells/well in 6 -well plates and resuspended at $2 \times 10^{6}$ to $5 \times 10^{6} \mathrm{cells} / \mathrm{mL}$ in serum-free DMEM and loaded with lysates from indicated TC1 (lysate from $1 \times 10^{4} \mathrm{TC1} / 4 \times 10^{4}$ BM-DC/mouse; Gal-3 ${ }^{\mathrm{HIGH}}$-vaccine: lysate with TC1-shCtrl; Gal-3 ${ }^{\text {LOW }}$-vaccine: lysate with TC1-shGal-3 or TC1-shCtrl pretreated in vitro for 15 days by LDD) in serum-free media for 3 hours at $37^{\circ} \mathrm{C}\left(5 \% \mathrm{CO}_{2}\right)$, and then adjuvants (PolyU-PEI (1:15; $20 \mu \mathrm{g} / \mathrm{mL}$ PolyU, Sigma)+CpG (2ng/ mL; IDT)) was added to allow an overnight maturation of BM-DC before mice injection.

\section{Lymphocyte proliferation}

For T-cell proliferation assays, $5 \times 10^{5} \mathrm{CFSE}$-stained murine lymph node cells $(2.5 \mu \mathrm{M}, 5 \mathrm{~min}$; Sigma) were seeded in a 96-well U-bottomed plate. Cells were then stimulated for 72 hours with coated anti-CD3 antibody $(1 \mu \mathrm{g} / \mathrm{mL}$, 145-2 C11 clon, BD Pharmingen) and proliferation assessed by CFSE dilution in presence of $5 \times 10^{4}$ autologous splenocytes and a variable number of tumor cells as indicated. Cells were then stained for CD8 (561093, BD Pharmingen) and for CD4 (22 $150046 \mathrm{sp}$, ImmunoTools) in staining buffer (PBS 1\% FBS, $0.01 \%$ sodium azide) for $30 \mathrm{~min}$ on ice, $(\mathrm{n}=3)$. Flow cytometry data acquisition was performed using a FACSAria (BD Biosciences) and analysis using the FlowJo software.

\section{Cytotoxic assays}

Killing of target cells was measured in lactate dehydrogenase (LDH)-release assay (Promega). LDH-release was measured in an enzymatic assay according to the manufacturers' protocol. Death of target cells or \% Cytotoxicity was calculated as follows $(\%$ Cytotoxicity $=($ Experimental 
- Effector Spontaneous - Target Spontaneous $\times 100$ )/ (Target Maximum - Target Spontaneous)), in which all values were normalized by subtraction of the LDH backgrounds originating from the spontaneous release of effector cells. Target cells (TC1 expressing (TC1-WT) or silenced for Gal-3 (TC1-shGal-3 or TC1-WT treated for 2 weeks with docetaxel $(1 \mathrm{nM})$, respectively) were used in this assay. Ten thousand target cells were added in a volume of $50 \mu \mathrm{l}$ well of a 96-well V-bottom microtiter plate. Lymphocytes from mice previously immunized with BM-DC vaccine (BM-DC pre-loaded with lysate from TC1shGal-3 (Gal-3 ${ }^{\left.\mathrm{LOW}_{\text {-vaccine }}\right)}$ or TC1-shCtrl $\left(\mathrm{Gal}-3^{\mathrm{HIGH}}\right.$ vaccine) as indicated, plus adjuvant (PolyU-PEI (1:15; $20 \mu \mathrm{g} / \mathrm{mL}$ PolyU $)+\mathrm{CpG}(2 \mathrm{ng} / \mathrm{mL}))$ as described before. A week later, immunized mice received an immune boost by injection of corresponding 200,000 TC1-shRNA in $200 \mu \mathrm{l}$ of PBS. Then, 5 days after the immune boost injection, mice were sacrificed and draining axillary, brachial and inguinal lymph nodes were recovered and homogenized using BIOFIL cell strainers and a syringe plunger on cold RPMI medium containing 10\% FBS (v/v). Cells were pelleted by centrifugation at $250 \mathrm{Xg}$ for $5 \mathrm{~min}$ and counted using a Neubauer chamber. Different Target:LN cells ratios were used as indicated in a final volume of $100 \mu \mathrm{L}$ of RPMI complete medium. The microtiter plates were centrifuged for $1 \mathrm{~min}$ at $250 \mathrm{Xg}$ and incubated for 4 hour at $37^{\circ} \mathrm{C}, 5 \% \mathrm{CO}_{2}$. Before harvesting $50 \mu \mathrm{l} /$ well of supernatant, plates were centrifuged again for $4 \mathrm{~min}$ at $250 \mathrm{Xg}$ and absorbance was measured at $492 \mathrm{~nm}$ by an iMARK microplate Reader (BIORAD).

\section{Statistical analysis}

Data are presented as mean $\pm S D$ of at least three separate experiments in triplicate. Comparisons between two groups were performed by using paired Student's t-test. For the analysis of the differences in tumor incidence, the $\chi^{2}$ statistic was applied. The comparison between $\%$ of tumor-free mice versus time (latency) was performed using the Gehan-Breslow-Wilcoxon test, based on a $\chi^{2}$ distribution. Differences were considered significant when $p$ values were less than 0.05 as shown in all figures when needed.

\section{RESULTS \\ Negative regulation of galectin-3 in PCa cell lines delays tumor growth and metastasis development in immunocompetent mice, but not in athymic nude mice}

To understand the apparent contradiction between the negative expression of Gal-3 in PCa primary tumors at advanced stages of the disease with the demonstrated roles of this galectin in the development of metastasis and aggressiveness of PCa cells, we designed a murine model using TC1 with a controlled Gal-3 expression. TRAMP-C mice and TC1 cells are widely used murine prostate cancer models that allow the use of syngeneic transplants to study immune responses in immunocompetent animals. ${ }^{589}$ We had already standardized a model based on the subcutaneous injection of TC1 to enable us to study various functional aspects of immune cells in PCa. ${ }^{55} 60$ This preclinical model has the advantage that tumor cells and hosts share the same genetic background, which allows the use of immunocompetent mice, which is more representative of what generally occurs in clinics. Also, we generated TC1 cells expressing different levels of Gal-3 using a lentivirus-derived shRNA expression (online supplemental table S1, figure 1A). TC1-shGal-3 cells showed a stable $95 \%$ decrease of the Gal-3 expression (Gal-3 $\left.3^{\mathrm{LOW}}-\mathrm{TC} 1\right)$ compared with the control-shRNA transduced cells that express high levels of this lectin (TC1-shCtrl, or Gal-3 $3^{\mathrm{HIGH}}$-TC1) (figure 1A).

We first verified that the high downregulation of Gal-3 expressed by TC1 cells led to the same and already wellcharacterized roles of this galectin, namely a decrease in both the tumorigenesis and metastases. Thus, evaluating the tumor growth for several weeks after subcutaneous inoculation of TC1-shGal-3 or TC1-shCtrl in C57BL/6 mice demonstrated a significant delay of $42 \pm 32$ days in the tumor apparition with lower tumorigenicity since fewer animals developed tumors when Gal-3 was silenced in tumor cells (figure 1B and table 1 No V1 vs No V2, $*(\mathrm{p}<0.01))$. Once the tumors appeared, no difference in tumor duplication time was observed (online supplemental table S2). We then analyzed the level of the Gal-3 expression in the resulting tumors to verify that the tumor growth was not due to recovered Gal-3, and showed that Gal-3 was still silenced in TC1-shGal-3-derived tumors (Gal-3 ${ }^{\mathrm{LOW}}$-tumors) compared with control (online supplemental figure S1a,b). Also, results show a high decrease in the apparition of metastasis (online supplemental table S2). All these results allowed us to validate our TC1 murine model.

The role of Gal-3 in controlling the function of immune cells in a variety of cancers prompted us to analyze tumor growth in athymic nude mice to evaluate further if the $\mathrm{T}$ cell compartment was responsible for these phenotypes. Our results demonstrated neither a delay nor a reduction of tumorigenicity or metastasis development between both tumor conditions (figure 1C, online supplemental table S2). Moreover, Gal- $3^{\mathrm{LOW}}$-tumor growth is faster in nude mice since duplication times are $11 \pm 1$ and $7 \pm 1$ days in TC1-shCtrl-derived and TC1-shGal-3-derived tumors, respectively (online supplemental table $\mathrm{S} 2, * *(\mathrm{p}<0.01)$ ). We thus hypothesized that Gal-3 expressed by tumor cells negatively controlled $\mathrm{T}$ cell functions to allow faster PCa growth and consequently metastasis development.

\section{Gal-3 expressed by tumor cells controls the tumor growth kinetic through its action on lymph node cells}

To further verify our hypothesis of Gal-3 controlling the immune cell functions, we decided to use preconditioned lymph node cells to evaluate if the delay on tumor growth could also be obtained by transferring the immunity induced by Gal- $3^{\mathrm{LOW}}$-TC1 (online supplemental figure S2). Briefly, TC1-shCtrl or TC1-shGal-3 cells were subcutaneously injected in C57BL/6 immunocompetent 
A

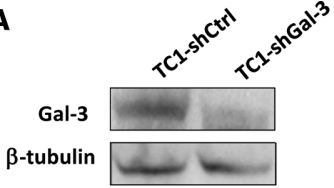

D
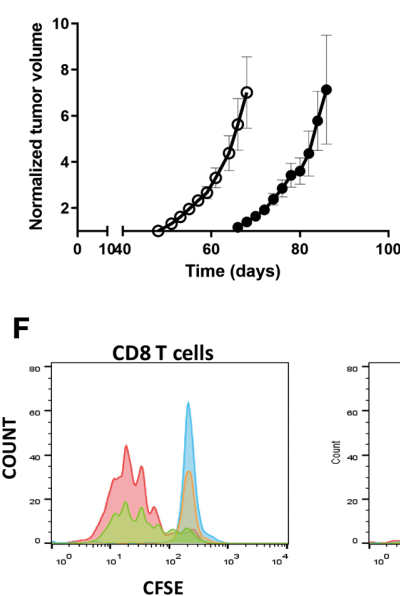

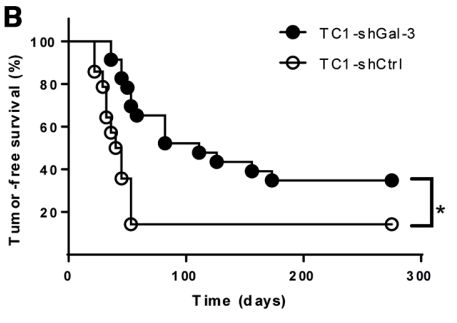

E
C

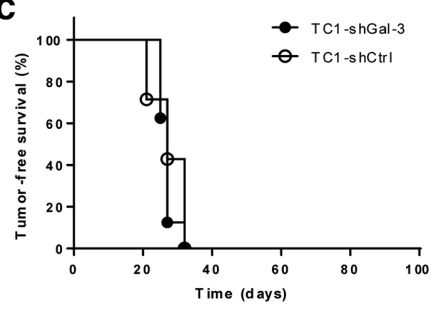

$\theta$ LN TC1-shCtrl - LN TC1-shGal-3

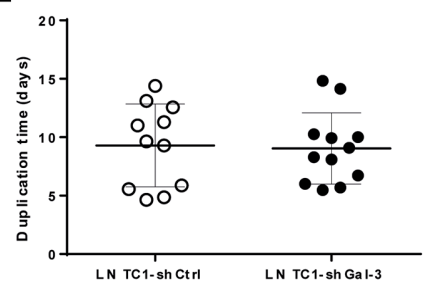

G
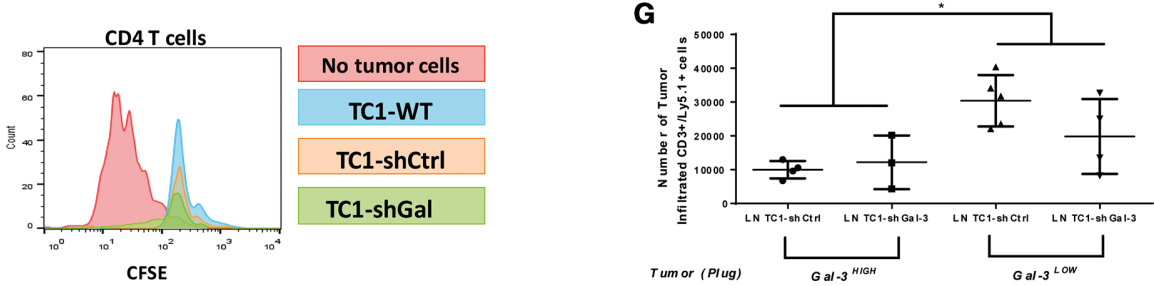

Figure 1 Effect of stable tumor Gal-3 silencing in prostate tumor growth and tumor cell infiltration. Determination of the level of expression of Gal-3 protein by Western blot (A). Tumor-free survival of TC1-shRNA subcutaneous inoculation in normal (B) or athymic nude (C) C57BL/6 mice (N; online supplemental table S2). Tumor expressing a normal level of Gal-3 (TC1-shCtrl) or silenced Gal-3 (TC1-shGal-3) were adoptive transferred with TC1-shCtrl preconditioned lymph node cells (LN TC1-shCtrl) or

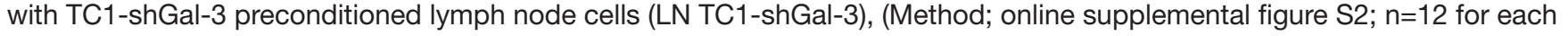
condition) (D to F). Two strains of C57BL/6 mice that differed in the gene variant of the CD45 molecule were used. The Ly5.1 donor strain expresses the CD45.1 variant while the Ly5.2 host strain expresses the CD45.2 variant, which allows the differential analysis of the donor and host cells. Tumor growth (TC1-shCtrl) was evaluated in Ly5.2 C57BL/6 mice by caliper-measured tumor volume (D). Evaluation of the resulting tumor growth by the time needed to duplicate the tumor volume (E). Proliferation assays were performed with lymph node cells isolated from naïve or immunized mice and co-cultured with autologous adherent spleen cells in the presence or not of tumor cells expressing different levels of Gal-3 (lymphocytes:tumor cell ratio, 20:1, $\mathrm{n}=3$ ). Non-immunized mice-lymphocytes were assayed for proliferation after polyclonal in vitro stimulation with coated anti-CD3 antibody $(1 \mu \mathrm{g} / \mathrm{mL})$ for 72 hours, and the proliferation rate was evaluated by dilution of CFSE intensity in the CD8+ or CD4+ Tcell populations $(F)$. Analysis by flow cytometry of CD3+ tumor infiltrated cells on day 5 post-adoptive transfer $(n=5)(G)$. ${ }^{*} p<0.05$ (Student's t-test). Gal-3,galectin-3; TC1, TRAMP-C1.

Ly5.1 donor mice in order to pre-stimulate immune cells by tumor cells expressing different levels of Gal-3. After 5 days, total donor lymph node cells (LN TC1-shCtrl or LN TC1-shGal-3) were harvested and adoptively transferred into sublethal irradiated Ly5.2 host mice injected the day before with tumor cells expressing wild type levels of Gal-3 (TC1-shCtrl). Results confirmed that the absence of Gal-3 in TC1 during the pre-stimulation of donor T cells (LN TC1-shGal-3) promotes a delay of tumor growth in the host mice (figure 1D), without affecting tumor duplication time significantly (figure $1 \mathrm{E}$ ), suggesting that the latency was not enough to promote a tumor cell selection by the immune pressure that would then affect the duplication time. Also, these results strongly suggested that Gal-3 expressed by the tumor cells interferes with the establishment of a protective immune response, and Gal-3 is thus necessary from the beginning of tumor growth.

\section{Gal-3 expressed by tumor cells controls the proliferation of activated CD8+ T cells}

A protective immune response could be evaluated first by the stimulation of $\mathrm{T}$ cell to proliferate. We thus analyzed the effect of TC1 expressing different levels of Gal-3, like other tumor cells, in inhibiting the proliferation of immune cells after an in vitro polyclonal activation. Briefly, CFSE-labeled lymph node cells were activated through a polyclonal manner by an anti-CD3 stimulation in the presence of TC1 cells expressing different levels of Gal-3 (figure 1F). As expected, the absence of tumor cells allows for the efficient proliferation of activated $\mathrm{T}$ cells, while the presence of $\mathrm{Gal}-3^{\mathrm{HIGH}}$-TC1 cells (wild-type or control tumor cells, TC1-WT or TC1-shCtrl, respectively) inhibits the $\mathrm{T}$ cell proliferation of both $\mathrm{CD} 4+$ and $\mathrm{CD} 8+$ $\mathrm{T}$ cells. More importantly, the silencing of Gal-3 in tumor cells (TC1-shGal-3) allows the recovery of the high proliferation of $\mathrm{CD} 8+\mathrm{T}$ cells but not of $\mathrm{CD} 4+\mathrm{T}$ cells (figure $1 \mathrm{~F}$ ). 
Table 1 Gal-3-silencing in prostate tumor cells by RNA interference or low/non-toxic doses of-docetaxel promotes vaccines' effectiveness

\begin{tabular}{|c|c|c|c|c|c|}
\hline & $\begin{array}{l}\text { Lysate used in } \\
\text { vaccine }\end{array}$ & Tumor & $\mathbf{N}$ & Tumor incidence (\%) & $\begin{array}{l}\text { Tumor free-survival } \\
\text { (days) }\end{array}$ \\
\hline No V1 & - & TC1-shGal-3 & 14 & $65^{\star}$ & $81 \pm 43^{*}$ \\
\hline No V3 & - & TC1-shCtrl/DTX & 10 & 80 & $49 \pm 7$ \\
\hline VP1 & TC1-shCtrl & TC1-shGal-3 & 10 & 70 & $116 \pm 29$ \\
\hline VP4 & TC1-shCtrl /DTX & TC1-shCtrl & 10 & 90 & $73 \pm 35$ \\
\hline VP5 & TC1-shGal-3 & TC1-shCtrl/DTX & 10 & 0 & $>275$ \\
\hline VP5.2 & TC1-shGal-3 & $\begin{array}{l}\text { TC1-shCtrl /DTX } \\
\text { +challenge }\end{array}$ & 5 & 0 & $>500$ \\
\hline
\end{tabular}

Tumor-bearing mice were vaccinated with BM-DC based vaccine loaded with tumor cells lysate expressing different levels of Gal-3 (Gal-3 ${ }^{\text {HIGH }}$ vaccine for TC1-shCtrl; or Gal-3 ${ }^{\text {LOW }}$-vaccine for TC1-shGal-3 and TC1-shCtrl/DTX) as indicated. The treatments with low and non-toxic doses of docetaxel (DTX) correspond to a $1 \mathrm{nM}$ dose in cultured cells during 2 weeks before processing into lysates or $0.83 \mathrm{mg} / \mathrm{kg}$ (intraperitoneal injection) during 2 weeks, once a week for treated mice.

${ }^{*} \mathrm{p}<0.05$.

BM, bone marrow; DC, dendritic cells; Gal-3, galectin-3; TC1, TRAMP-C1.

Altogether the results support the hypothesis that Gal-3 expressed by tumor cells is a critical factor of the delay of tumor growth by promoting the activation and proliferation of antitumor CD8+ T cells. This information is essential to benefit patients with prostate cancer.

\section{Gal-3 expressed by tumor cells decreases the number of tumor-infiltrated T cells without inducing their apoptosis}

Not only CD8+ T cells need to proliferate, but they have to infiltrate tumors. Since Gal-3 expressed by tumor cells has a major impact on early events of lymphocyte activation and proliferation occurring in draining lymph nodes, we decided to evaluate the impact of such phenomena on the number of TIL able to infiltrate tumors expressing wild type or down-regulated Gal-3 (Gal-3 ${ }^{\mathrm{HIGH}}$-tumors vs GAL- ${ }^{\mathrm{LOW}}$-tumors, respectively). For this and as previously described (online supplemental figure S2), we used the adoptive transfer of Ly5.1 donor lymph node cells (LN) previously preconditioned by TC1-shCtrl or -shGal-3 (LN TC1-shCtrl or LN TC1-shGal-3, respectively). In order to differentiate host from donor cells, donor LN were transferred into Ly5.2 mice hosts -bearing Gal- $3^{\mathrm{HIGH}}$ - or Gal- $3^{\text {LOW }}$-tumor cells in matrigel plug. On day 6 after adoptive transfer, matrigel-plugs allowed us to harvest cells from tumor microenvironment to characterize the TIL. Results show that the number of donor TIL (CD3+/ Ly5.1+) were significantly increased in plugs containing Gal-3 ${ }^{\mathrm{LOW}}$-tumor compared with those containing control tumor cells (Gal-3 ${ }^{\mathrm{HIGH}}$-tumor) (figure $1 \mathrm{G}$ ), suggesting that Gal-3 expressed by the tumor cells is likely an inhibitor of TIL infiltration, but not of TIL activation (online supplemental figure S3). Moreover, galectins are also known to induce apoptosis of T cells, and this effect could explain this difference in TIL number. We thus assayed for Annexin V/PI labeling and show that Gal-3 $3^{\mathrm{HIGH}_{-}}$ tumors do not induce a significant difference in apoptosis of CD3+ cells compared with Gal- $3^{\mathrm{LOW}}$-tumors (data not shown). Since the tumor has been characterized as an immune-privileged microenvironment, we hypothesized that Gal-3 expressed by PCa cells is mainly an inhibitor of $\mathrm{T}$ cell proliferation in lymph nodes and tumor infiltration.

\section{A highly effective antitumor vaccine based on Gal- $3^{\text {LOW }}$ prostate cancer cell lysate-loaded dendritic cells}

To date, immunotherapy has garnered major interest in prostate cancer therapy, but all immunotherapies, including Sipuleucel-T (the only vaccine authorized by the FDA for asymptomatic patients with PCa) and other immunotherapies, using anti-checkpoint antibodies, had failed to show high efficiency against PCa growth or recurrence. ${ }^{12861}$ We hypothesized that the expression of Gal-3 by tumor cells could interfere with $\mathrm{T}$ cell behavior and thus with vaccine efficiency, and wondered if a therapeutic process similar to Sipuleucel-T, using BM-DC loaded with a Gal- $3^{\mathrm{LOW}}-\mathrm{PCa}$ cell lysate, could be used as an effective vaccine to control PCa tumor growth. To test our hypothesis, we prepared TC1 lysates from TC1shGal-3 or TC1-shCtrl cells by three successive cycles of freezing and thawing to allow for the complete tumor cell lysis. Autologous BM-DC were loaded with these lysates independently and matured overnight with adjuvants prior to being used as a vaccine and before the inoculation of Gal-3 $3^{\mathrm{LOW}}-\mathrm{TC1}$ cells in $\mathrm{C} 57 \mathrm{BL} / 6$ naive mice (figure 2A). Remarkably, the vaccine based on BM-DC loaded with a Gal-3-positive PCa cell lysate (VP1) allowed a delay in the growth of Gal-3 $3^{\mathrm{LOW}}$-tumors compared with the unvaccinated mice (No V1), 116 \pm 29 days versus $81 \pm 43$ days, respectively (figure 2B, table 1: VP1 vs No 


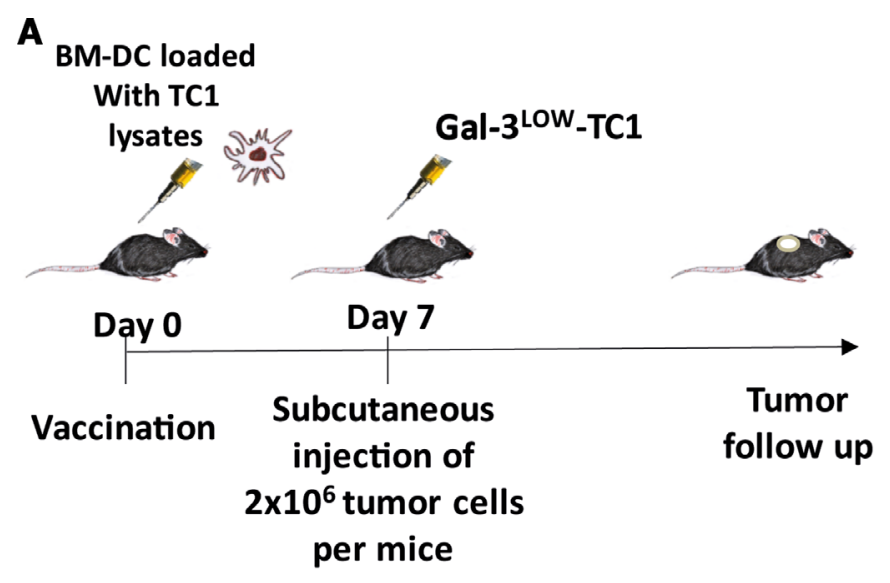

B

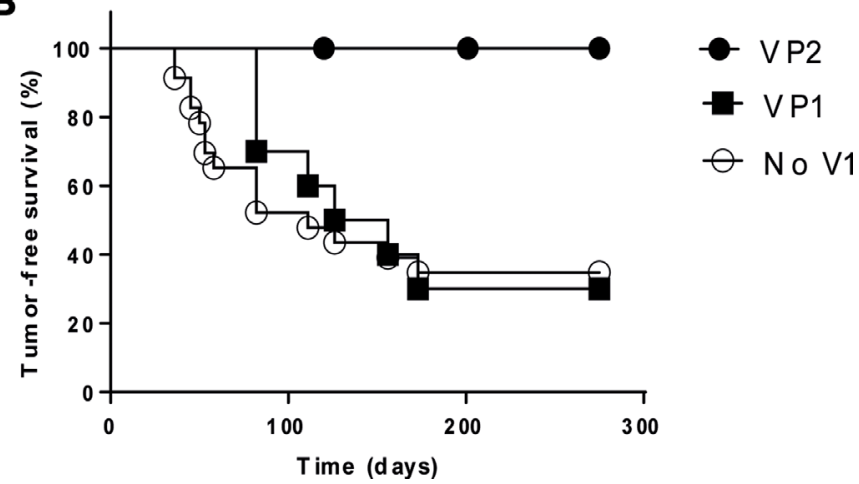

Figure 2 Cellular lysates of Gal-3 $3^{\text {LOW }}$ tumor cells promote an efficient autologous dendritic cell-based vaccine against Gal-3-silenced prostate tumors. Protocol of vaccination uses autologous BM-DC loaded with prostate cancer cell lysates expressing a different level of Gal-3 (A). Effect of different cellular lysates on the growth of a Gal-3-silenced TC1 tumor (TC1-shGal-3), (VP1: lysate from TC1-shCtrl; VP2: lysate from TC1-shGal-3; No V1: not vaccinated mice) (B). BM, bone marrow; DC, dendritic cells; Gal-3, galectin-3; TC1,TRAMP-C1.

V1). This VP1 vaccine is similar to the currently used tumor lysate-pulsed DC-based approaches. It is unlikely that the nature of the lysate might regulate BM-DC properties as a mechanism to explain the different efficiency between $\mathrm{Gal}-3^{\mathrm{HIGH}}$ and $\mathrm{Gal}-3^{\mathrm{LOW}}$ vaccine. In fact, the analysis of the phenotype and functionality of BM-DC (online supplemental figure S4) after incubation with different lysates did not reveal any particular modulation of these BM-DC to act as professional APC to prime naïve $\mathrm{T}$ cells. This result suggests that lectin canonical activity of Gal-3 cannot explain the resulting vaccine potentiation. However, Gal-3 was also demonstrated to participate in gene expression and splicing as well, ${ }^{6263}$ justifying further studies to identify potential Gal-3-target genes that could serve as new tumor-associated antigens, and to explain the high efficiency of this therapeutic vaccine. More interestingly, our results using a vaccine consisting in BM-DC loaded with a lysate from Gal- $3^{\mathrm{LOW}}-\mathrm{TC} 1$ cells
(VP2), demonstrated complete inhibition of the tumor growth of cognate Gal- $3^{\mathrm{LOW}}-\mathrm{TC} 1$ cells, delay superior to 275 days (time of the animal euthanasia) compared with the no vaccination condition (figure $2 \mathrm{~B}$, table 1 : VP2 vs No V1). Altogether, these results reveal the level of Gal-3 expression by PCa cells as a key parameter for the success of immunotherapy.

\section{Docetaxel treatment promotes the decrease of the Gal- 3 expression in prostate tumor cells and patients with metastatic $\mathrm{mCRPC}$ as well}

Our study went further intending to translate research findings rapidly into clinical settings. Since the use of interference RNA as therapeutics to control Gal-3 in patient's tumors is not easily feasible in the clinics, we examined how the expression of Gal-3 could be decreased in patients to promote preconditioning of the tumor microenvironment, and thus allowing the success of immunotherapy. Our previous study of PCa resistance to taxane had revealed docetaxel as an interesting pretreatment to silence Gal-3. ${ }^{64}$ Docetaxel is well-known to interfere with microtubule depolymerization, promoting cell cycle arrest and cell death, ${ }^{65}$ and it is widely used as a chemotherapeutic agent against $\mathrm{PCa}$ in patients and thus rapidly transferable to a clinical protocol. To verify in our TC1 model these preliminary data obtained with human PCa cell lines, we first analyzed the survival of TC1 cells at different doses of docetaxel and confirmed that TC1 cells are sensitive to taxane treatments $(\mathrm{EC} 50=8.10 \pm 0.03 \mathrm{nM}$ ) (figure 3A). Again, when we analyzed the expression of Gal-1 and Gal-3 (as the most expressed and immunoregulatory galectins in $\mathrm{PCa}^{29}$ ), we found that Gal-3 expression, among other genes, sharply decreased in TC1 cells treated with low doses of docetaxel compared with cells under vehicle treatment, both in vitro (figure $3 \mathrm{~B}$ ) and in tumors (figure 3C). In contrast, the expression of Gal-1 was not modified by docetaxel treatment (figure 3B,C). More importantly, the docetaxel-mediated negative regulation of the Gal-3 expression was also confirmed in metastasis samples of patients with chemotherapytreated mCRPC (figure 3D), and it did not significantly affect the expression of Gal-1. Since Gal-3 is a well-known galectin that could interfere with the immune system, ${ }^{39-43}$ and docetaxel-based chemotherapy promotes immunotherapy success in PCa patients, ${ }^{51}{ }^{52}$ we thus hypothesized that docetaxel acts, in part, through Gal-3 silencing in prostate tumor cells, which could be helpful for translational medicine.

\section{In mCRPC patient samples, docetaxel-based chemotherapy induces Th1 but not pro-inflammatory gene expression profiles}

Although cancer chemotherapy leads to leukocyte aplasia and has always been considered immunosuppressive, numerous clinical and preclinical examples show that certain taxane-based chemotherapies may increase the efficacy of immunotherapies. ${ }^{45-52}$ Also, the high level of cell death is likely owed to how chemotherapy promotes 

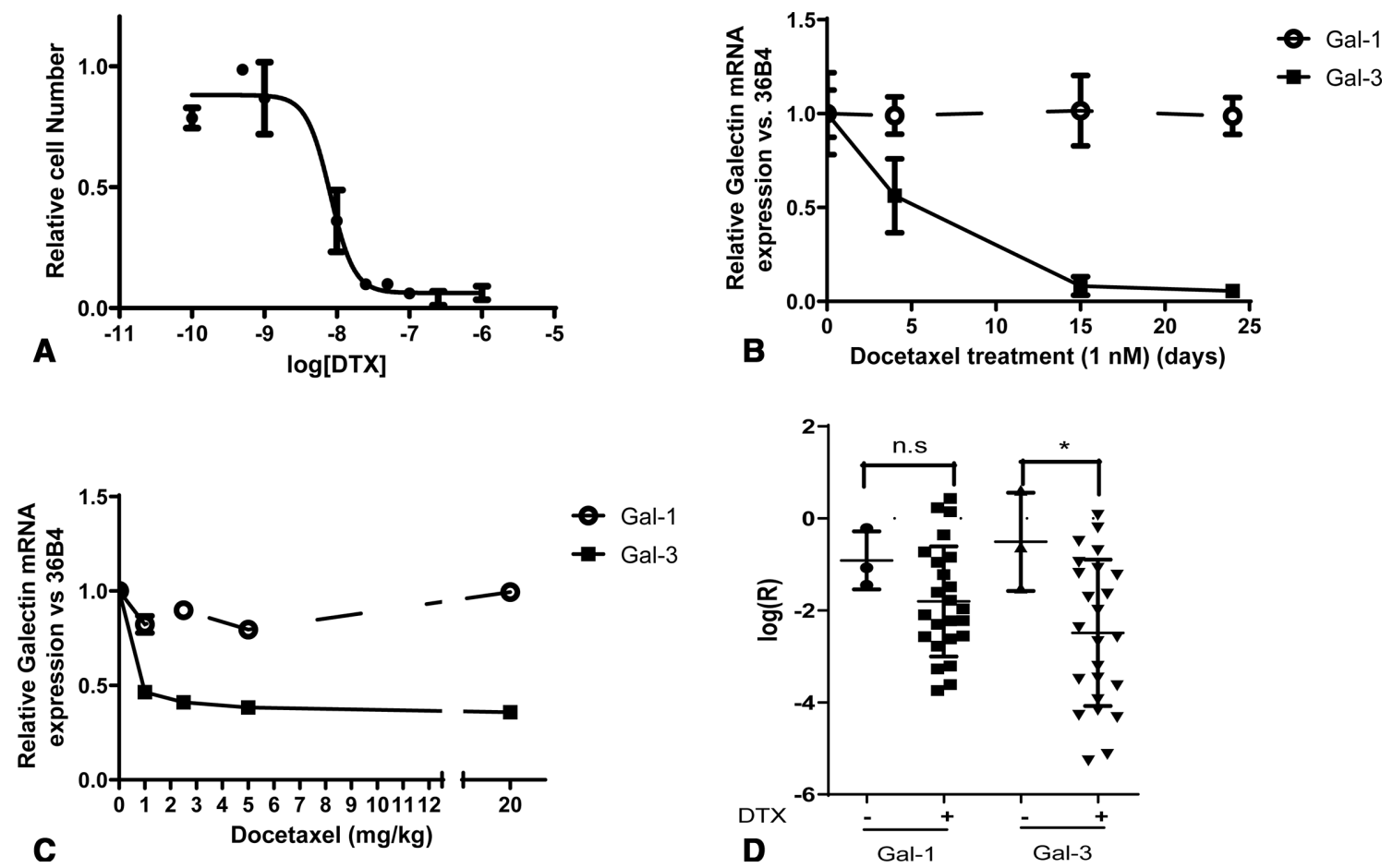

Figure 3 Docetaxel-based chemotherapy induces Gal-3 expression decrease in prostate tumor cells and in patients with mCRPC. Dose-dependent cytotoxic effect of docetaxel on TC1 in vitro (A). Docetaxel promotes Gal-3 silencing in TC1 cells without affecting Gal-1 expression in vitro (B) and in vivo (C), and in metastatic samples of patients with mCRPC using a microarray database (GSE35988) (D) ${ }^{54}{ }^{*} \mathrm{p}<0.05$. DTX, docetaxel;Gal-1, galectin-1; Gal-3, galectin-3; mCRPC, metastatic and castration-resistant PCa; mRNA, messenger RNA; n.s, not significant difference; PCa, prostate cancer; TC1, TRAMP-C1.

a pro-inflammatory microenvironment that achieves additive or synergistic clinical activity with immunotherapy. To date, no study confirms the promotion of an inflammatory microenvironment, especially in patients with PCa. Herein, we thus analyzed the expression of a panel of pro-inflammatory genes in metastasis samples of patients with mCRPC that have or have not undergone chemotherapy protocols. The results in figure 4 clearly show that the expression of any of the well-characterized pro-inflammatory genes is not modified when analyzed in patients with mCRPC treated and untreated with docetaxel (figure 4A). To go further in our investigation, we also analyzed cytokines/chemokines gene expression and confirmed that IL-4, IL-10, TGF- $\beta$, and IL-17 genes (as Th2 and Th17 profiles, respectively) showed no significant variation (figure 4B). In contrast-and more importantly-interleukin 2 and interferon gamma (IFN $\gamma$ ), as well as the Perforin genes (characteristic of a Th1 profile), significantly increased when patients with mCRPC received chemotherapy (figure 4C). These results strongly suggest that docetaxel-based chemotherapy could favor a Th1 immune response independently from pro-inflammatory genes promotion in patients with mCRPC, but involving other immune controlling factors such as Gal-3.

\section{Gal-3 negative regulation in tumor cells is a critical factor in the success of vaccine-based immunotherapy}

Previously, we have shown that a Gal-3-silenced PCa cell lysate used in a BM-DC-based vaccine interferes with the growth of Gal-3 $3^{\mathrm{LOW}}$ tumors (figure $2 \mathrm{~B}$ ). With the goal of translational research, we first wondered which preconditioning treatment with docetaxel before vaccination could strongly decrease the expression of Gal-3 in tumors without affecting the viability of immune cells. We thus sought to analyze the survival of immune cells at different doses of DTX. Results in figure 5 show that in vivo CD8+ T cells (figure 5A) are sensitive to taxane treatments, while CD4+ T cells are less sensitive (figure 5B), but no significant effect on the viability of any type of the $\mathrm{T}$ cells was observed at doses as low as $0.83 \mathrm{mg} / \mathrm{kg}$, which we defined as the LDD to be used in the following experiments. This result prompted us to analyze whether this LDD, inducing Gal-3 decrease in TC1, enables the same vaccine efficiency seen with previously tested RNA interference strategy (TC1-shGal-3). For this purpose, we tested if a lysate obtained from LDD-pretreated tumor cells (TC1-shCtrl/ DTX) could conclusively be used in a DC-based vaccine to control TC1 tumor growth (figure 5C). As shown in figure $5 \mathrm{D}$, we observed that such a vaccination (VP4) induced a delay in the growth of $\mathrm{Gal}-3^{\mathrm{HIGH}}$-tumors but failed to fully protect the animals (VP4 vs No V3, figure $5 \mathrm{D}$, table $1 ; 73 \pm 35$ days vs $49 \pm 7$ days, respectively). Again, BM-DC pulsed with a lysate from LDD-pretreated TC1 cells (TC1-shCtrl/DTX) or with Gal-3-silenced TC1 cells completely inhibited Gal-3 ${ }^{\mathrm{LOW}}$-tumor growth (figure 5D, table 1; VP3 and VP5, tumors TC1-shGal-3 or TC1-shCtrl/ DTX). This inhibition of tumor growth is similar to the antitumoral effect obtained with the TC1-shGal-3 vaccine 
A
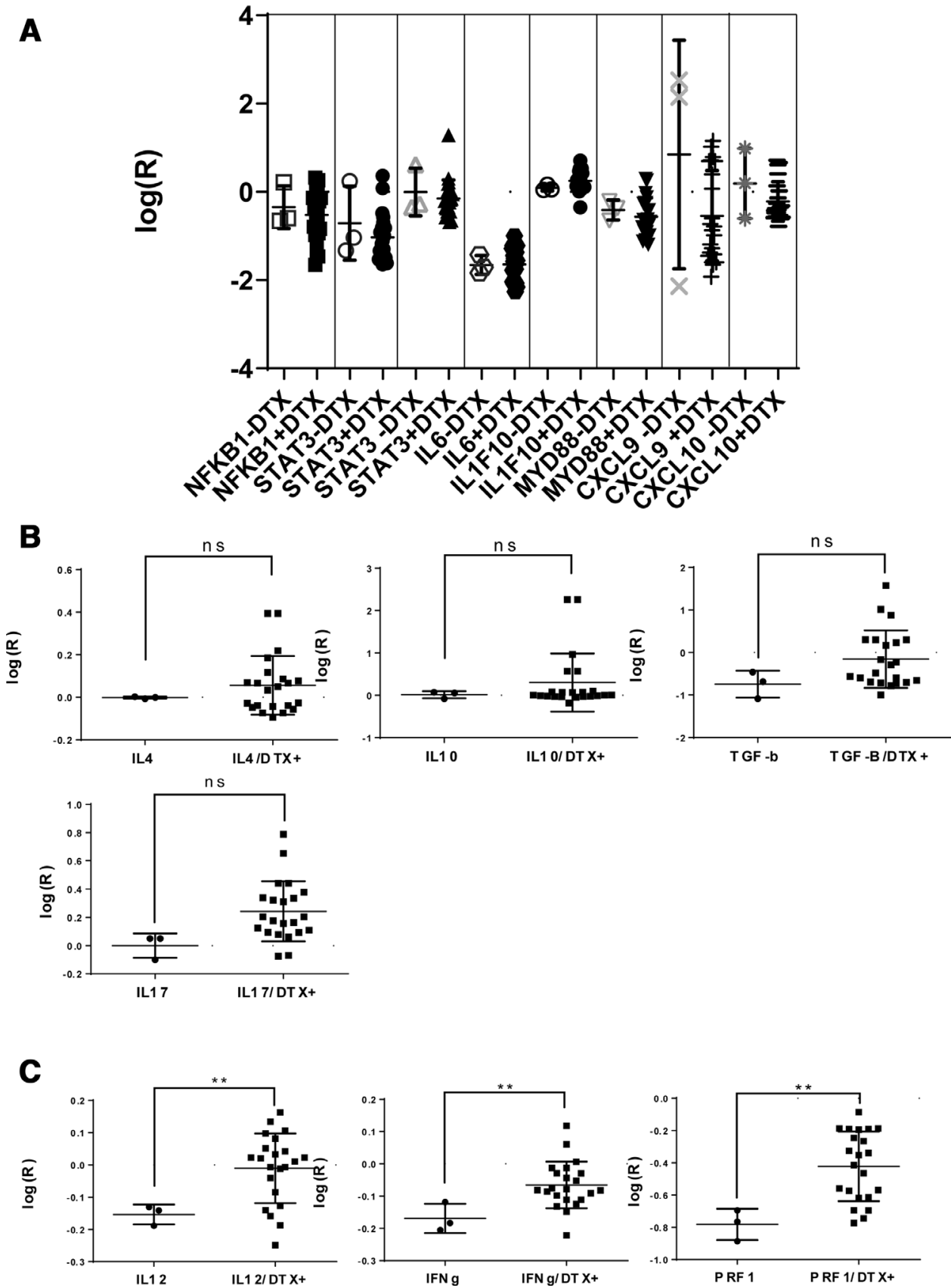

Figure 4 High-throughput analysis of metastasis transcriptome from metastatic samples of patients with mCRPC, treated or not by docetaxel-based chemotherapy. Gene expressions in patients treated with docetaxel (DTX+) or untreated for proinflammatory genes (A), for cytokines/chemokines gene expressions for Th2 or Th17 (B) or Th1 profiles (C), using microarray database (GSE35988). ${ }^{54} \mathrm{IL}$, interleukin; IFN g, interferon gamma; mCRPC, metastatic and castration-resistant prostate cancer.

(VP2, figure 2B, table 1), and strongly suggests that the main effect of docetaxel is similar to Gal-3 silencing to interfere with the Gal-3 expression by tumor cells. Interestingly, a second injection of Gal- $3^{\mathrm{LOW}}$-TC1 cells, as tumor challenge, 1 year after the VP5 vaccination still showed complete and long-term protection of mice from tumor growth (table 1, VP5.2). Altogether, these results show that the expression of Gal-3 by PCa tumors is a crucial parameter for the success of immunotherapy since Gal-3 expressed by the tumor is likely the leading cause of prostate cancer immunotherapy failure.
Vaccination with Gal-3 ${ }^{\text {LOW }}$-prostate cancer cell lysate loaded DC activates cytotoxic CD8+ T cells and reduces the number of CD8+-TRegs but not CD4+-TRegs.

To further challenge our hypothesis that the vaccination success in the absence of Gal-3 was due to the effective activation of an anticancer immune response, we performed tumor infiltration analysis and cytotoxicity assays with $\mathrm{T}$ cells isolated from immunized mice. Since $\mathrm{PCa}$ is also characterized by a high level of TReg infiltration, ${ }^{5-7}$ the induction and differentiation of TReg by Gal-3 expressed by tumor cells are important parameters 
A

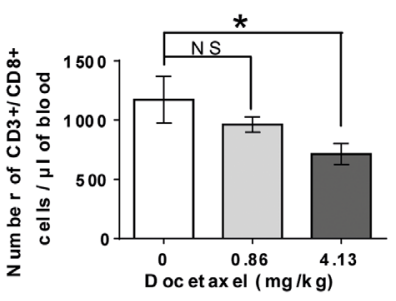

B

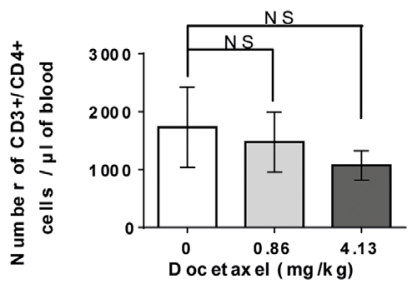

C. BM-DCloaded

With TC1 lysates

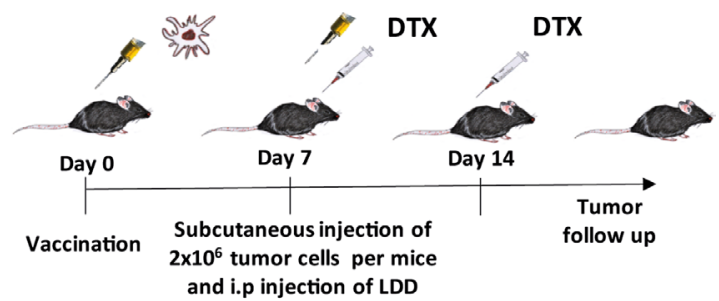

D

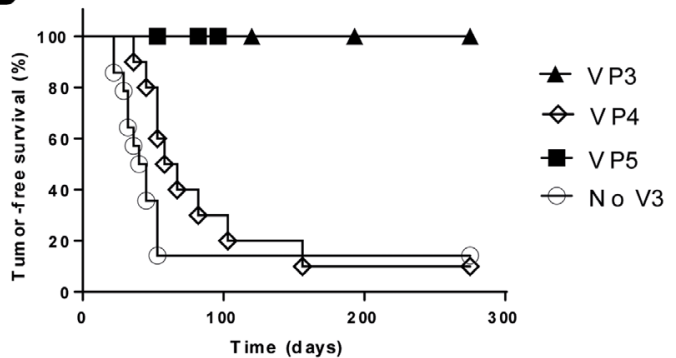

F

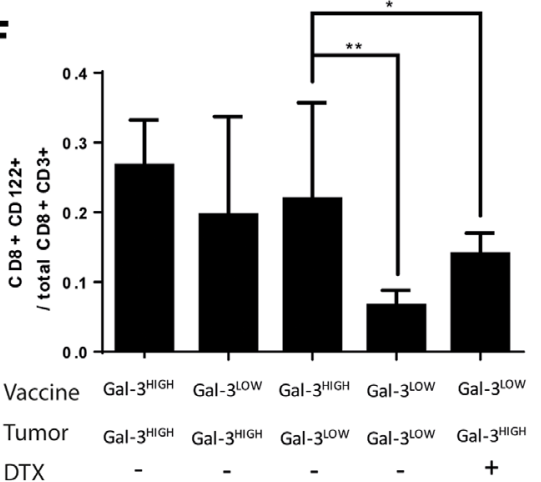

G

E

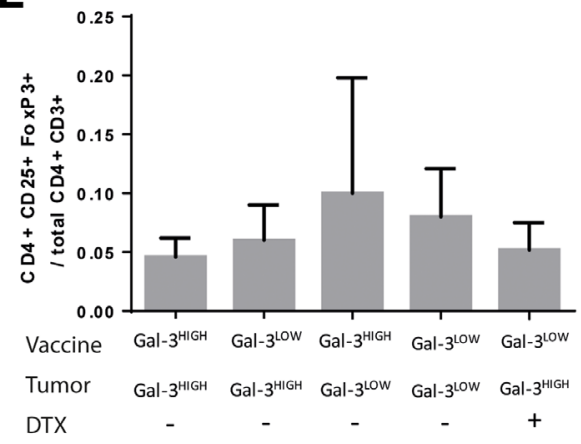

Figure 5 Low and non-toxic doses of docetaxel decrease Gal-3 expression in prostate tumor cells without affecting T cell viability and promote effective vaccine against prostate tumors. Dose-dependent cytotoxic effect of docetaxel on the in vivo viability of circulating CD8+ T cells (A) and CD4+ T cells (B). Combinatory protocol of vaccination and docetaxel treatment (C) and its effect on mice survival after prostate tumor challenge (D) when the expression of tumor Gal-3 was silenced by stable RNA interference (shGal-3)(VP3) or after docetaxel pre-treatment (VP5); or not silenced (VP4) or without vaccination (No V3) (see table 1 for details). Analysis of TReg/total T cell ratios of purified TIL from vaccinated mice bearing different Gal-3-expressing TC1 tumors, on CD4+ $(E)$ and CD8+ $(F)$ compartment $(n=3)$. Ex vivo cytotoxic assays of splenocytes from vaccinated mice with BM-DC loaded with control (white bars) or negatively-regulated Gal-3 (black bars) TC1 lysates against TC1 targets expressing different levels of Gal-3. Representative bar graphs at three different Target:Effector ratios for three independent experiments are shown (G). BM, bone marrow; DC, dendritic cells; DTX, docetaxel;Gal-3,galectin-3; LDD, low and non-toxic doses of DTX; NS, not significant difference; TC1, TRAMP-C1; TIL, tumor-infiltratinglymphocytes.

that may impact tumor development. It is well known that CD4+CD25+Foxp3+TRegs (CD4TReg) suppress cytotoxic CD8+ Tcell function. Moreover, CD8+ TRegs strongly suppress immune functions in cancer; ${ }^{66-69}$ these cells infiltrate tumors and metastatic sites and are associated with poor patient survival. ${ }^{68} 70$ However, no study has evaluated their suppressive dependence on Gals.

Their inhibitory function depends on Galectin expression (eg, essentially Gal- ${ }^{22}$ ). Since the Gal-1 expression is not modified in TC1-shGal-3 and patients treated 
with docetaxel, we thus wondered whether Gal-3 could have the same function to promote PCa immune tolerance. Then, we decided further to study the levels of CD4TReg (CD4+CD25+Foxp3+) and CD8TReg (CD8 $+\mathrm{CD} 122+\mathrm{CD} 28-)$ in the prostate tumor microenvironment depending on the level of Gal-3 expression. For this, mice bearing Gal-3-expressing or Gal-3-silenced TC1 tumors (Gal-3 ${ }^{\mathrm{HIGH}}$ or Gal-3 ${ }^{\mathrm{LOW}}$-tumor, respectively) were treated or not with LDD (DTX + or -) before vaccination to allow preconditioning of tumor microenvironment for Gal-3 negative regulation. These mice were then vaccinated with BM-DC vaccine loaded with different TC1 lysate (from TC1-shGal-3 (Vaccine Gal-3 ${ }^{\mathrm{LOW}}$ ) or TC1-shCtrl (Vaccine Gal- $\left.3^{\mathrm{HIGH}}\right)$ ). These mice were finally evaluated for the infiltrating TReg/total T cells ratios: CD4TReg versus total CD4+ T cells or CD8TReg versus total CD8+ $\mathrm{T}$ cells (figure 5D,E). Despite the slight and insignificant differences observed in the CD4+ Tcell population (figure 5E), the ratio between CD8TReg versus total CD8+ T cells significantly decreased in Gal-3 $3^{\mathrm{LOW}}$ tumors (Tumor Gal-3 ${ }^{\text {LOW }}$ or LDD-treated tumors (Tumor Gal-3 $3^{\mathrm{HIGH}}$, DTX+)) and mice vaccinated in the absence of Gal-3 (vaccine Gal-3 ${ }^{\mathrm{LOW}}$ ) (figure $5 \mathrm{~F}$ ). Interestingly, the expression of Gal-3 should also be weak in the lysate that loaded BM-DCs (Vaccine Gal-3 ${ }^{\mathrm{LOW}}$ ) to control tumor growth effectively. Again, vaccination with the lysate from TC1-shCtrl (vaccine $\mathrm{Gal}-3^{\mathrm{HIGH}}$ ) only delayed $\mathrm{Gal}-3^{\mathrm{LOW}}$-tumor growth like the VP1 (table 1) and was unable to decrease the ratio of CD8TReg to total CD8+ T cells (figure 5F). In contrast, this ratio was significantly decreased with vaccination involving lysate from Gal- $3^{\mathrm{LOW}}-\mathrm{TC1}$, independently of the way of Gal-3 downregulation (RNA interference or LDD pretreatment). This result could give some information about the cellular mechanism of how such a vaccination controlled the growth of Gal-3 $3^{\mathrm{LOW}}$ tumors (VP2 and VP3, table 1). Moreover, results confirm that Gal-3 expressed by tumor cells plays a key role in allowing high levels of CD8TReg that inhibit CD8+ T cell proliferation and functions, empowering tumor immune escape, and consequently PCa growth. More importantly, the success of the vaccination is again likely dependent on the Gal-3 negative status of the tumor. To go further in this functional study, we decided to confirm that Gal- $3{ }^{\mathrm{HIGH}}$-tumors affect the resultant cytotoxicity of the activated CD8+ T cells. For this, we analyzed antitumor cytotoxicity after vaccination using $\mathrm{LDH}$ release assays (figure $5 \mathrm{G}$ ). As results, vaccination with $\mathrm{BM}-\mathrm{DC}$ loaded with a $\mathrm{Gal}-3^{\mathrm{HIGH}}-\mathrm{TC} 1$ lysate (white bars) promotes the killing of cognate target cells (eg, TC1 WT that express normal levels of Gal-3), while vaccination with BM-DC loaded with Gal- $3^{\text {LOW }}-\mathrm{TC} 1$ lysate (black bars) is much more effective (figure 5G). Again, a low level of Gal-3 expression by tumor cells defines the increased activity of PCa-specific cytotoxic $\mathrm{T}$ cells (figure 5G). Altogether, these results support the assumption that the negative regulation of Gal-3 in prostate tumor cells is primordial to negatively control the number of CD8TReg cells, empowering antitumor CD8+ $\mathrm{T}$ lymphocyte functions, and finally, promotes the success of the vaccination. Our results thus support that Gal-3 is a negative immune checkpoint controlling the functions of anti-PCa T cells. Interestingly, Gal-3 can be silenced easily by a preconditioning treatment with LDD before vaccination.

\section{A preconditioning treatment with low and non-toxic doses of docetaxel prior to immunotherapy is useful to lead to an effective therapeutic vaccine against prostate cancer}

We confirmed that the expression of Gal-3 by the tumor is one of the key parameters responsible for the failure of immunotherapy against PCa. Since LDD interfere with the expression of this galectin by prostate tumor cells but do not promote cell death (neither tumor cells nor, more importantly, immune cells), we decided to test whether intraperitoneal injections of LDD before vaccination could protect prostate tumor-bearing animals by improving the immunotherapy efficiency. For this purpose, we used a therapeutic preclinical model that involves a tumor resection surgery that mimics prostatectomy usually performed in patients. Then, tumor-resected mice were treated once a week for 2 weeks with LDD $(0.83 \mathrm{mg} / \mathrm{kg}$, 47-time less compared with the corresponding chemotherapeutic doses used in humans, (http://www.fda.gov/ cder/guidance/index.html)) (figure 6). This preconditioning treatment on day 4 after the tumor resection (DR, figure 6) allows negative Gal-3 regulation in the remaining tumor cells (likely circulating tumor cells) before vaccination with an autologous BM-DC loaded by a Gal-3 ${ }^{\text {LOW }}$-TC1 lysate (figure 6A, table 2). We finally evaluated the tumor recurrence in those animals. Without any vaccination, the results in table 2 show that LDD-induced decrease of the Gal-3 expression in tumor cells is insufficient to control Gal-3 $3^{\mathrm{HIH}}$-tumor growth since four from seven treated animals showed recurrence of the primary tumor growth (No V5 vs No V4, table 2).

Interestingly, LDD-dependent-Gal-3 downregulation is sufficient to control metastasis development, as well as with Gal-3-silenced tumors (online supplemental figure S1c). Besides, vaccination with an autologous BM-DC loaded with a Gal- ${ }^{\mathrm{LOW}}-\mathrm{TC1}$ lysate as unique treatment was inefficient over a long period of time to completely inhibit tumor recurrence after the tumor resection (VT1, table 2). More importantly, preconditioning of the tumor microenvironment with an LDD treatment right after primary tumor resection and before vaccination is essential to allow immunotherapy to control PCa tumor growth, as demonstrated by the absence of tumor recurrence in a vast majority of mice (six out of seven) treated with the combinatory approach (VT2, table 2). It is thus unlikely that Gal-3 expressed by prostate tumor cells directly influences the metastatic progression or the tumorigenicity of PCa cell lines, but more importantly, promotes the suppressive function of the CD8+CD122+CD28T cells and thus the inhibition of antitumor CD8+ Tcell cytotoxic activity (figure 6B). Finally, chemotherapy based on LDD before immunotherapy allows long-term tumor-free outcomes in a vast majority of animals. This protocol could be easily 


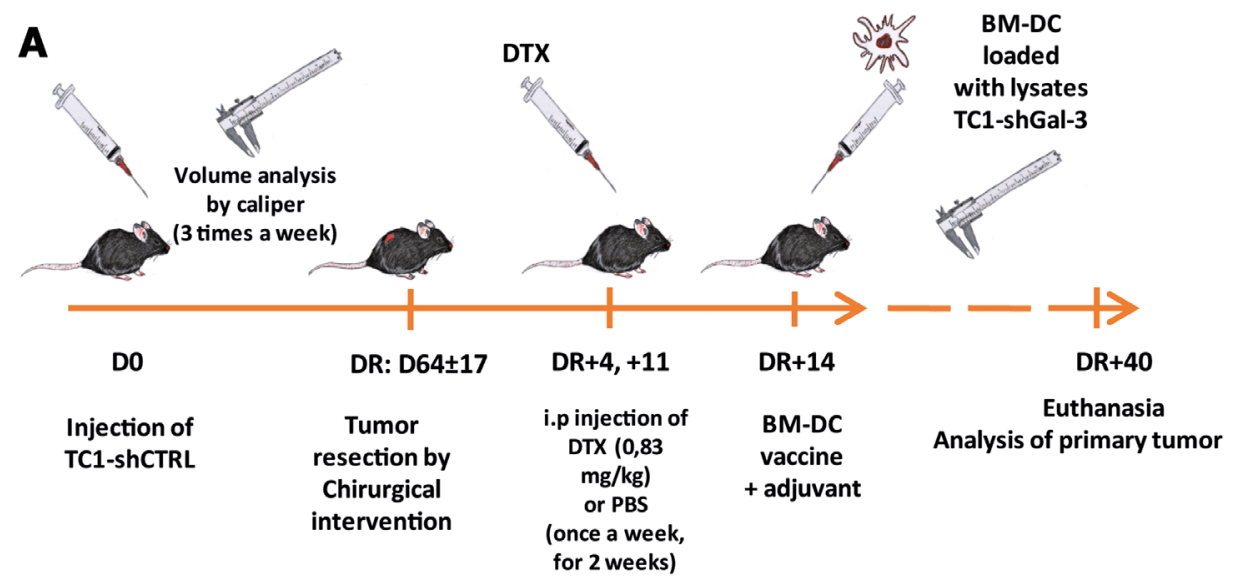

B
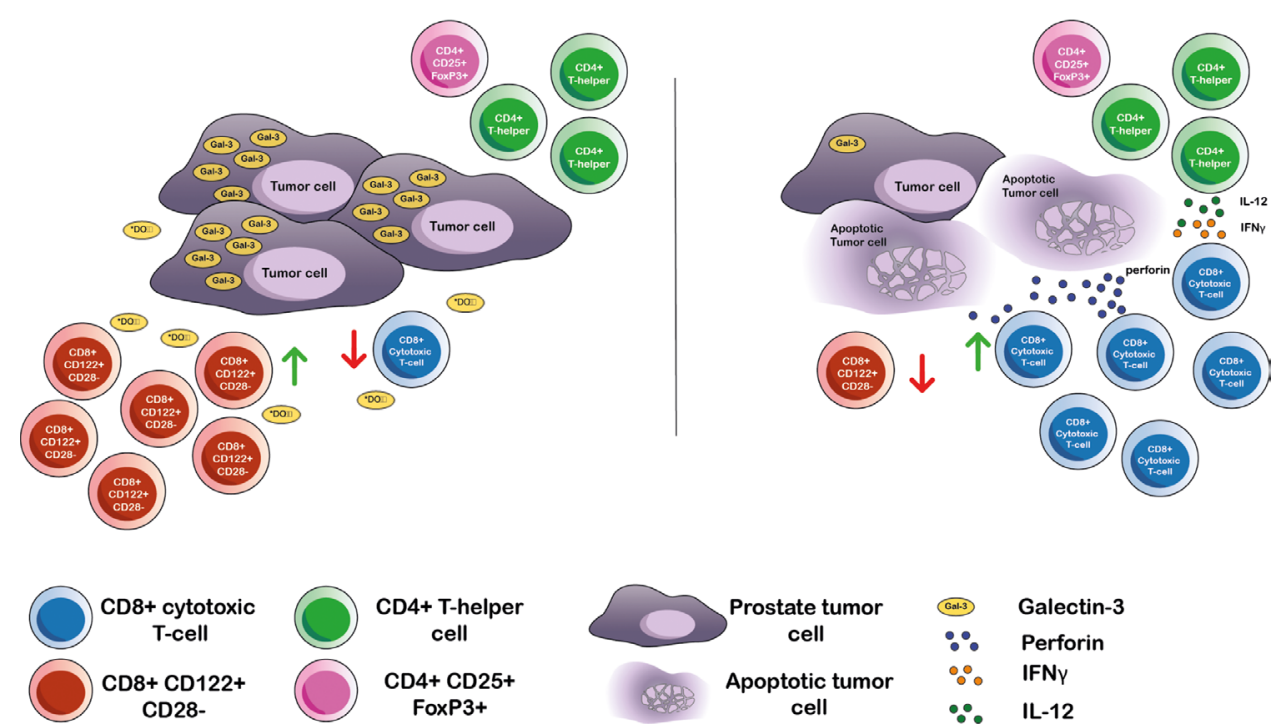

$\begin{array}{cl}\text { (ain3 } & \text { Galectin-3 } \\ \because & \text { Perforin } \\ \because & \text { IFNY } \\ \because & \text { IL-12 }\end{array}$

Figure 6 In vivo treatment with low and non-toxic doses of docetaxel prior to a BM-DC vaccination leads to effective immunotherapy against PCa, preventing tumor recurrence. Protocol of surgical tumor resection followed by autologous BMDC vaccination, combined or not with docetaxel treatment $(0.83 \mathrm{mg} / \mathrm{kg}$, once a week for 2 weeks $)$ prior to vaccination, and evaluation of tumor recurrence (A). Two-week treatment with low and nontoxic doses of Docetaxel (LDD) leads to a strong decrease in the expression of Gal-3 by tumor cells. When vaccinated with BM-DC loaded with Gal-3 ${ }^{\text {Low }}$-tumor cell lysate, mice subjected to LDD treatment (right) showed a decrease in the CD8+CD122+CD28-/total CD8+ cells ratio in comparison to non-pre-treated mice (left), while the CD4+CD25+FoxP3+ (CD4Treg)/total CD4+ cells ratio remained constant. Moreover, metastatic samples of patients with MCRPC treated with this chemotherapy presented increased expression of genes that favor an effective cytotoxic response, like perforin and Th1 profile cytokines/chemokines (B). BM, bone marrow; DC, dendritic cells; DTX, docetaxel;Gal-3,galectin-3; IL, interleukin; IFN g, interferon gamma;mCRPC, metastatic and castration-resistant PCa;PBS, phosphate-buffered saline; PCa, prostate cancer; TC1,TRAMP-C1.

transferable to clinical settings to treat all PCa patients as soon as they suffered a prostatectomy surgery.

\section{DISCUSSION AND CONCLUSIONS}

In this study, we have addressed conflicting findings of the role of Gal-3 and its downregulation in primary prostate cancer samples. We thus propose Gal-3 as a fundamental player in the immune escape, which causes unsuccessful vaccine therapy. We first demonstrated that Gal-3 is indirectly responsible for the aggressiveness of prostate cancer cells and the metastasis development through its control of the immune system. This finding defines Gal-3 as a new negative immune checkpoint. Then, we also described how docetaxel-based chemotherapy positively affects the effectiveness of immunotherapy against PCa. Our results show that docetaxel treatment negatively regulates the 
Table 2 Combination of low and non-toxic doses of docetaxel and therapeutic immunotherapy leads to the inhibition of prostate tumor recurrence and metastasis

\begin{tabular}{|c|c|c|c|c|c|c|}
\hline & BM-DC vaccine & Tumor & LDD & $\begin{array}{l}\text { Primary tumor } \\
\text { recurrence }\end{array}$ & $\begin{array}{l}\text { Metastasis } \\
\text { development }\end{array}$ & Observations \\
\hline No V4 & - & Gal-3 $3^{\mathrm{HIGH}}$ & - & $7 / 8$ & $7 / 8$ & Steatosis \\
\hline VT1 & Gal-3 $3^{\text {LOW }}$ & Gal-3 $3^{\text {HIGH }}$ & - & $4 / 7$ & $4 / 7$ & Increased lymph node size \\
\hline VT2 & Gal-3 $3^{\text {LOW }}$ & Gal-3 ${ }^{\text {HIGH }}$ & + & $1 / 7$ & $0 / 7$ & Increased lymph node size \\
\hline
\end{tabular}

Gal-3 ${ }^{\mathrm{HIGH}}$ tumor-bearing mice underwent tumor resection surgery 4 days before receiving or not intraperitoneal injections of low and non-toxic doses of docetaxel (LDD: $0.83 \mathrm{mg} / \mathrm{kg}$ during 2 weeks, once a week), and then all tumor-resected mice were vaccinated with BM-DC-based vaccine loaded by Gal-3 ${ }^{\text {LOW }}$-tumor cells lysate (TC1-shGal-3) or not as indicated. Observations were made after the sacrifice of the animals. $\mathrm{BM}$, bone marrow; DC, dendritic cells; Gal-3, galectin-3; LDD, low and non-toxic doses of docetaxel.

Gal-3 expression on tumor cells. This biological effect results in potentiating the response of the immune system to an effective anti-PCa vaccination, positioning Gal-3 as a major negative checkpoint of the immune response that allows PCa growth and aggressiveness. These results match previous bibliographic data suggesting a correlation between the level of the Gal-3 expression by the tumor and poor prognosis for patients with $\mathrm{PCa} .{ }^{30-32} \mathrm{It}$ is exciting that docetaxel still regulates the Gal-3 expression also in taxane-resistant PCa cells. This finding allows us to propose a functional combinatory therapeutic protocol against tumor recurrence for all patients with PCa.

Galectins have already been shown to be proteins involved in controlling immune responses in a broad range of diseases. ${ }^{44}$ Most reports on cancer have focused on Gal-1 and its effect on immune escape, but it must be emphasized that different galectin members can have different and sometimes opposite effects on $\mathrm{T}$ cell behavior. ${ }^{20}$ Gal-3 has been shown strongly expressed by PCa primary tumors at the beginning of the disease and decreases up to the complete switch-off of its expression at advanced stages ${ }^{29}{ }^{72}$ suggesting its primary function is to control the priming of the antitumor immune response at the very early stages of the disease. We also showed here that this particular galectin recovers its expression in metastasis samples of patients with mCRPC. However, while we confirmed the correlation between Gal-3 expression and poor prognosis for patients with $\mathrm{PCa}$, further studies are needed to understand if Gal-3 recovers its expression in metastases or if only Gal-3-positive PCa cells could take out of the primary tissue to spread. In this study, we showed for the first time that Gal-3 is required for prostate tumor cells to establish and maintain immune tolerance and that this occurs through inducing the deregulation of CD8+ T cell cytotoxic responses. Ideally, an effective antitumor vaccine requires the correct priming of naive $\mathrm{T}$ cells, which, in turn, acquires effector functions that enable the eradication of tumor cells. The data in the literature demonstrate that cytotoxic CD8+ T cells are the main cell type whose presence in infiltrates is associated with better prognosis in all types of cancers. ${ }^{73}$ Our results show for the first time that Gal-3 negative regulation in tumor cells (accomplished by two different strategies: Docetaxel treatment or a more specific method using lentivirus-drived stable RNA interference) allows the efficient activation and proliferation of CD8+ cytotoxic $\mathrm{T}$ cells by decreasing the ratio between $\mathrm{CD} 8+\mathrm{CD} 122+\mathrm{CD} 28-$ TRegs and total $\mathrm{CD} 8+\mathrm{T}$ cells. In agreement, it has been reported that Gal-3 in a tumor microenvironment could inhibit CD4 and CD8 T cell functions. ${ }^{74}$ More importantly, GordonAlonso and collaborators showed that Gal-3 secreted by tumor cells sequesters the IFN $\gamma$ in the stroma; ${ }^{43}$ the use of various Gal-3 inhibitors allow this cytokine to induce a correct Th1 polarization and the cytotoxic activity of $\mathrm{T}$ cells in different tumor models and patients as well. Our high-throughput analysis of gene expression shows that docetaxel chemotherapy decreases Gal-3 expression in mCRPC patient samples and promotes the expression of Th1 and cytotoxic genes such as perforin. Altogether, these data support tumor-derived Gal-3 as a critical negative checkpoint of the anti-PCa immune response, promoting the tumor-infiltration of a high number of CD8+CD122+CD28- regulatory $\mathrm{T}$ cells that finally inhibits the cytotoxic functions of antitumor CD8+ T cells.

Recently, it has been observed that Taxol derivatesbased chemotherapy has a positive influence on cancer immunotherapy. In fact, some reports revealed that docetaxel treatment promotes the survival of activated $\mathrm{T}$ cells in colons, ${ }^{46}$ Lewis lung, ${ }^{45}$ and metastatic breast ${ }^{49}$ cancers. We found that low and non-toxic doses of this taxane (a 47-times lower dose than that currently used in chemotherapeutic protocols) neither promote lymphopenia nor induce the death of tumor cells (figures 5A,B and $3 \mathrm{~A}$, respectively). However, treatment with these LDD strongly decreases the expression of Gal-3 by tumor cells, among other genes, both in vitro and in vivo, leading to an active antitumor CD8+ T cell expansion with cytotoxic functions and tumor infiltration. This finding may have a high impact on the development of vaccine-based immunotherapies for PCa. Given the limited success of the only immunotherapy approved for patients with mCRPC (Sipuleucel-T; overall survival of 4.1 months $^{12}$ ) and the absence of a response of all other immunotherapies against $\mathrm{PCa}$, our results suggest that the Gal-3 expression by tumor cells or circulating prostate tumor cells could be 
one of the reasons for the ineffectiveness of these strategies for treating patients with PCa.

Our results suggest that the efficiency of a DC-based vaccine against PCa strongly depends on the Gal-3 status of the tumor. Since primary tumors in advanced PCa are mostly Gal-3 downregulated, it is conceivable that these phases of the disease are favorable to immunotherapy. However, the decreased expression of Gal-3 was only identified in primary prostate tumors but not in mCRPC samples, and no data exist on the level of expression of this galectin in corresponding circulating tumor cells (CTC), the remaining cells after tumor resection or prostatectomy. It is likely that the expression of Gal-3 might be controlled before patients with PCa undergo immunotherapy protocols. Unfortunately, the reduced number of CTC in patients with PCa does not easily allow this kind of pre-analysis. ${ }^{75}$ Gal-3 could then be used not only as a bad prognosis for patients with PCa but also as a marker of immunotherapy resistance. Finally, the examination of the few anticancer clinical trials involving galectins shows Gal-3 as a critical target, ${ }^{28}$ but none of the ongoing trials already combined Gal-3 inhibitors before therapeutic vaccination. We thus propose that patients should take advantage of pretreatment with low and non-toxic doses of docetaxel to decrease the Gal-3 expression in the remaining tumor cells prior to vaccination to improve immunotherapy success.

\section{DECLARATIONS}

\section{Study design and approvals}

Using an immune-competent, subcutaneous and metastatic animal model of prostate cancer, we assessed the therapeutic benefit of adding a pre-treatment of low and non-cytotoxic doses docetaxel (LDD, as indicated) to inhibit Gal-3 expression before vaccination to promote tumor-free outcomes. The ability of this combination therapy to control local and systemic disease relapse as tumor recurrence was evaluated in comparison with single or absence of treatment protocols. To elucidate the mechanism responsible for enhanced therapy, we characterized effects of treatment on the tumor microenvironment and lymph nodes in our in vivo model using flow cytometry and in vitro assays of primary culture cells. Studies using animal were performed in accordance with the Institutional Animal Care and Use Committee guidelines, authorized by (IAUCC protocol \#2016-038, FCEyN, Buenos Aires, Argentina) and Animal procedures complied with the Guidelines for the Welfare of Animals in Experimental neoplasia (UK). Data set from human samples used in our high-throughput analysis was approved and patients consent were included in the original publication. ${ }^{54}$

\section{Twitter Diego José Laderach @DiegoLaderach}

Acknowledgements The authors wish to express special thanks to Dr Javier Cotignola, Lics Guillermo Piazza, Ignacio Gonzalez-Perez and Gustavo Carrizo (IQUIBICEN-CONICET; QB-FCEN-UBA, Argentina) for technical help; the staff at the
FCEN-Central Animal Facility for animal husbandry, Dr Hong and Roffo hospital's nurses (Roffo hospital, CABA, Argentina) for drugs (docetaxel was kindly gifted from Roffo hospital) and advice; Sophie Tartare-Deckert and Marcel Deckert from French laboratories for helpful scientific discussions and support. The authors also want to thank the INSERM and Molecular Mediterranean Medicine Center (C3M) - NiceSophia Antipolis University-Faculty of Sciences (Nice), Victor Ségalen University / IDEX(Bordeaux) and Paris-Diderot University-Epigenetic and Cell Fate Center (Paris), all from France.

Contributors Acquisition analysis and interpretation of data: CDT, LDG, CV, EC, FMJ, DJL and DC. Statistic analysis of data: CDT, LDG, CV and DC. Material support: DJL, AC and DC. Development of methodology: DJL and DC. Conception, design and supervision of the study: DC. Writing of the paper: DC. Review of the paper: DJL, CDT, AC and DC.

Funding This work was supported by the Fundación Fiorini from Argentina (Grant number Compagno 2017), and Worldwide Cancer Research from Scotland (Grant number WCR18-0095).

Competing interests None declared.

Patient consent for publication Not required.

Provenance and peer review Not commissioned; externally peer reviewed.

Data availability statement All data relevant to the study are included in the article or uploaded as supplementary informations.

Supplemental material This content has been supplied by the author(s). It has not been vetted by BMJ Publishing Group Limited (BMJ) and may not have been peer-reviewed. Any opinions or recommendations discussed are solely those of the author(s) and are not endorsed by BMJ. BMJ disclaims all liability and responsibility arising from any reliance placed on the content. Where the content includes any translated material, BMJ does not warrant the accuracy and reliability of the translations (including but not limited to local regulations, clinical guidelines, terminology, drug names and drug dosages), and is not responsible for any error and/or omissions arising from translation and adaptation or otherwise.

Open access This is an open access article distributed in accordance with the Creative Commons Attribution Non Commercial (CC BY-NC 4.0) license, which permits others to distribute, remix, adapt, build upon this work non-commercially, and license their derivative works on different terms, provided the original work is properly cited, appropriate credit is given, any changes made indicated, and the use is non-commercial. See http://creativecommons.org/licenses/by-nc/4.0/.

ORCID iD

Daniel Compagno http://orcid.org/0000-0002-7589-7217

\section{REFERENCES}

1 Grainger S, Traver D, Willert K. Wnt signaling in hematological malignancies. Prog Mol Biol Trans/ Sci 2018;153:321-41.

2 Denmeade SR, Isaacs JT. A history of prostate cancer treatment. Nat Rev Cancer 2002;2:389-96.

3 Maia MC, Hansen AR. A comprehensive review of immunotherapies in prostate cancer. Crit Rev Oncol Hematol 2017;113:292-303.

4 Bronte V, Kasic T, Gri G, et al. Boosting antitumor responses of T lymphocytes infiltrating human prostate cancers. J Exp Med 2005;201:1257-68.

5 Miller AM, Lundberg K, Ozenci V, et al. CD4+CD25high T cells are enriched in the tumor and peripheral blood of prostate cancer patients. J Immunol 2006;177:7398-405.

6 Kiniwa Y, Miyahara Y, Wang HY, et al. CD8+ Foxp3+ regulatory T cells mediate immunosuppression in prostate cancer. Clin Cancer Res 2007;13:6947-58.

7 Sfanos KS, Bruno TC, Maris $\mathrm{CH}$, et al. Phenotypic analysis of prostate-infiltrating lymphocytes reveals $\mathrm{TH} 17$ and Treg skewing. Clin Cancer Res 2008;14:3254-61.

8 Drake CG. Prostate cancer as a model for tumour immunotherapy. Nat Rev Immunol 2010;10:580-93.

9 Drake CG, Antonarakis ES. Current status of immunological approaches for the treatment of prostate cancer. Curr Opin Urol 2012;22:197-202.

10 Gulley JL, Drake CG. Immunotherapy for prostate cancer: recent advances, lessons learned, and areas for further research. Clin Cancer Res 2011;17:3884-91.

11 Higano CS, Schellhammer PF, Small EJ, et al. Integrated data from 2 randomized, double-blind, placebo-controlled, phase 3 trials of 
active cellular immunotherapy with sipuleucel-T in advanced prostate cancer. Cancer 2009;115:3670-9.

12 Kantoff PW, Higano CS, Shore ND, et al. Sipuleucel-T immunotherapy for castration-resistant prostate cancer. N Engl J Med 2010;363:411-22.

13 Suárez C, Morales-Barrera R, Ramos V, et al. Role of immunotherapy in castration-resistant prostate cancer (CRPC). BJU Int 2014;113:367-75.

14 Hodi FS, O'Day SJ, McDermott DF, et al. Improved survival with ipilimumab in patients with metastatic melanoma. $N$ Engl $J$ Med 2010;363:711-23.

15 Brahmer JR, Tykodi SS, Chow LQM, et al. Safety and activity of anti-PD-L1 antibody in patients with advanced cancer. N Engl J Med 2012;366:2455-65.

16 Topalian SL, Hodi FS, Brahmer JR, et al. Safety, activity, and immune correlates of anti-PD-1 antibody in cancer. N Engl $J$ Med 2012;366:2443-54.

17 Wolchok JD, Hodi FS, Weber JS, et al. Development of ipilimumab: a novel immunotherapeutic approach for the treatment of advanced melanoma. Ann N Y Acad Sci 2013;1291:1-13.

18 Kwek SS, Cha E, Fong L. Unmasking the immune recognition of prostate cancer with CTLA4 blockade. Nat Rev Cancer 2012;12:289-97.

19 Rabinovich GA, Croci DO. Regulatory circuits mediated by lectin-glycan interactions in autoimmunity and cancer. Immunity 2012;36:322-35.

20 Cedeno-Laurent F, Dimitroff CJ. Galectins and their ligands: negative regulators of anti-tumor immunity. Glycoconj J 2012;29:619-25.

21 Toscano MA, Bianco GA, llarregui JM, et al. Differential glycosylation of $\mathrm{TH} 1, \mathrm{TH} 2$ and $\mathrm{TH}-17$ effector cells selectively regulates susceptibility to cell death. Nat Immunol 2007;8:825-34.

22 Garín MI, Chu C-C, Golshayan D, et al. Galectin-1: a key effector of regulation mediated by CD4+CD25+ T cells. Blood 2007;109:2058-65.

23 Bollyky PL, Wu RP, Falk BA, et al. ECM components guide IL-10 producing regulatory T-cell (TR1) induction from effector memory T-cell precursors. Proc Natl Acad Sci U S A 2011;108:7938-43.

24 Okano M, Satoskar AR, Nishizaki K, et al. Induction of Th2 responses and IgE is largely due to carbohydrates functioning as adjuvants on Schistosoma mansoni egg antigens. J Immunol 1999;163:6712-7.

25 Zhu B, Trikudanathan S, Zozulya AL, et al. Immune modulation by Lacto-N-fucopentaose III in experimental autoimmune encephalomyelitis. Clin Immunol 2012;142:351-61.

26 Ilarregui JM, Croci DO, Bianco GA, et al. Tolerogenic signals delivered by dendritic cells to T cells through a galectin-1-driven immunoregulatory circuit involving interleukin 27 and interleukin 10. Nat Immunol 2009;10:981-91.

27 Caldwell S, Heitger A, Shen W, et al. Mechanisms of ganglioside inhibition of APC function. J Immunol 2003;171:1676-83.

28 Compagno D, Tiraboschi C, Garcia JD, et al. Galectins as checkpoints of the immune system in cancers, their clinical relevance, and implication in clinical trials. Biomolecules 2020;10. doi:10.3390/biom10050750. [Epub ahead of print: 1205 2020].

29 Laderach DJ, Gentilini LD, Giribaldi L, et al. A unique galectin signature in human prostate cancer progression suggests galectin-1 as a key target for treatment of advanced disease. Cancer Res 2013;73:86-96.

30 Merseburger AS, Kramer MW, Hennenlotter J, et al. Involvement of decreased Galectin-3 expression in the pathogenesis and progression of prostate cancer. Prostate 2008;68:72-7.

31 Wang $Y$, Nangia-Makker $P$, Tait $L$, et al. Regulation of prostate cancer progression by galectin-3. Am J Pathol 2009;174:1515-23.

32 Knapp JS, Lokeshwar SD, Vogel U, et al. Galectin-3 expression in prostate cancer and benign prostate tissues: correlation with biochemical recurrence. World J Urol 2013;31:351-8.

33 Davidson PJ, Davis MJ, Patterson RJ, et al. Shuttling of galectin-3 between the nucleus and cytoplasm. Glycobiology 2002;12:329-37.

34 Carvalho RS, Fernandes VC, Nepomuceno TC, et al. Characterization of LGALS3 (galectin-3) as a player in DNA damage response. Cancer Biol Ther 2014;15:840-50.

35 Fritsch K, Mernberger M, Nist A, et al. Galectin-3 interacts with components of the nuclear ribonucleoprotein complex. BMC Cancer 2016;16:502.

36 Patterson RJ, Haudek KC, Voss PG, et al. Examination of the role of galectins in pre-mRNA splicing. Methods Mol Biol 2015;1207:431-49

37 Cardoso ACF, Andrade LNdeS, Bustos SO, et al. Galectin-3 determines tumor cell adaptive strategies in stressed tumor microenvironments. Front Oncol 2016;6:127.

38 Nangia-Makker P, Hogan V, Raz A. Galectin-3 and cancer stemness. Glycobiology 2018;28:172-81.
39 Ruvolo PP. Galectin 3 as a guardian of the tumor microenvironment. Biochim Biophys Acta 2016;1863:427-37.

40 Demotte N, Stroobant V, Courtoy PJ, et al. Restoring the association of the T cell receptor with CD8 reverses anergy in human tumorinfiltrating lymphocytes. Immunity 2008;28:414-24.

41 Wang W, Guo H, Geng J, et al. Tumor-released galectin-3, a soluble inhibitory ligand of human NKp30, plays an important role in tumor escape from NK cell attack. J Biol Chem 2014;289:33311-9.

42 Kouo T, Huang L, Pucsek AB, et al. Galectin-3 shapes antitumor immune responses by suppressing CD8+ T cells via LAG-3 and inhibiting expansion of plasmacytoid dendritic cells. Cancer Immunol Res 2015;3:412-23.

43 Gordon-Alonso M, Hirsch T, Wildmann C, et al. Galectin-3 captures interferon-gamma in the tumor matrix reducing chemokine gradient production and T-cell tumor infiltration. Nat Commun 2017;8:793.

44 Farhad M, Rolig AS, Redmond WL. The role of galectin-3 in modulating tumor growth and immunosuppression within the tumor microenvironment. Oncoimmunology 2018;7:e1434467.

45 Chu Y, Wang L-X, Yang G, et al. Efficacy of GM-CSF-producing tumor vaccine after docetaxel chemotherapy in mice bearing established Lewis lung carcinoma. J Immunother 2006;29:367-80.

46 Garnett CT, Schlom J, Hodge JW. Combination of docetaxel and recombinant vaccine enhances T-cell responses and antitumor activity: effects of docetaxel on immune enhancement. Clin Cancer Res 2008;14:3536-44.

47 Eralp Y, Wang X, Wang J-P, et al. Doxorubicin and paclitaxel enhance the antitumor efficacy of vaccines directed against her 2/ neu in a murine mammary carcinoma model. Breast Cancer Res 2004;6:R275-83.

48 Kodumudi KN, Woan K, Gilvary DL, et al. A novel chemoimmunomodulating property of docetaxel: suppression of myeloid-derived suppressor cells in tumor bearers. Clin Cancer Res 2010;16:4583-94.

49 Heery CR, Ibrahim NK, Arlen PM, et al. Docetaxel alone or in combination with a therapeutic cancer vaccine (PANVAC) in patients with metastatic breast cancer: a randomized clinical trial. JAMA Oncol 2015;1:1087-95.

50 Hodge JW, Garnett CT, Farsaci B, et al. Chemotherapy-Induced immunogenic modulation of tumor cells enhances killing by cytotoxic T lymphocytes and is distinct from immunogenic cell death. Int $J$ Cancer 2013;133:624-36.

51 Slovin S. Chemotherapy and immunotherapy combination in advanced prostate cancer. Clin Adv Hematol Oncol 2012;10:90-100.

52 Slovin SR. Toward maximizing immunotherapy in metastatic castration-resistant prostate cancer - rationale for combinatorial approaches using chemotherapy. Front Oncol 2012;2:43.

53 Compagno D, Merle C, Morin A, et al. siRNA-directed in vivo silencing of androgen receptor inhibits the growth of castrationresistant prostate carcinomas. PLoS One 2007;2:e1006.

54 Grasso CS, Wu Y-M, Robinson DR, et al. The mutational landscape of lethal castration-resistant prostate cancer. Nature 2012;487:239-43.

55 Jaworski FM, Gentilini LD, Gueron G, et al. In Vivo Hemin Conditioning Targets the Vascular and Immunologic Compartments and Restrains Prostate Tumor Development. Clin Cancer Res 2017;23:5135-48.

56 Prins RM, Shu CJ, Radu CG, et al. Anti-Tumor activity and trafficking of self, tumor-specific T cells against tumors located in the brain. Cancer Immunol Immunother 2008;57:1279-89.

57 Tavaré R, Escuin-Ordinas H, Mok S, et al. An effective ImmunoPET imaging method to monitor CD8-Dependent responses to immunotherapy. Cancer Res 2016;76:73-82.

58 Greenberg NM, DeMayo F, Finegold MJ, et al. Prostate cancer in a transgenic mouse. Proc Natl Acad Sci U S A 1995;92:3439-43.

59 Foster BA, Gingrich JR, Kwon ED, et al. Characterization of prostatic epithelial cell lines derived from transgenic adenocarcinoma of the mouse prostate (TRAMP) model. Cancer Res 1997;57:3325-30.

60 Gentilini LD, Jaworski FM, Tiraboschi C, et al. Stable and high expression of Galectin-8 tightly controls metastatic progression of prostate cancer. Oncotarget 2017;8:44654-68.

61 Isaacsson Velho P, Antonarakis ES. PD-1/PD-L1 pathway inhibitors in advanced prostate cancer. Expert Rev Clin Pharmacol 2018:11:475-86.

62 Dagher SF, Wang JL, Patterson RJ. Identification of galectin-3 as a factor in pre-mRNA splicing. Proc Natl Acad Sci U S A 1995;92:1213-7.

63 Haudek KC, Voss PG, Locascio LE, et al. A mechanism for incorporation of galectin-3 into the spliceosome through its association with U1 snRNP. Biochemistry 2009;48:7705-12. 
64 Garrido MF, Martin NJ-P, Bertrand M, et al. Regulation of elF4F translation initiation complex by the peptidyl prolyl isomerase FKBP7 in taxane-resistant prostate cancer. Clin Cancer Res 2019;25:710-23.

65 Suzuki A, Kawabata T, Kato M. Necessity of interleukin-1 beta converting enzyme cascade in taxotere-initiated death signaling. Eur $J$ Pharmacol 1998;343:87-92.

66 Yu P, Steel JC, Zhang M, et al. Simultaneous inhibition of two regulatory T-cell subsets enhanced Interleukin-15 efficacy in a prostate tumor model. Proc Natl Acad Sci U S A 2012;109:6187-92.

67 Parodi A, Battaglia F, Kalli F, et al. CD39 is highly involved in mediating the suppression activity of tumor-infiltrating CD8+ $T$ regulatory lymphocytes. Cancer Immunol Immunother 2013;62:851-62.

68 Filaci G, Fenoglio D, Fravega M, et al. CD8+ CD28- T regulatory lymphocytes inhibiting $T$ cell proliferative and cytotoxic functions infiltrate human cancers. J Immunol 2007;179:4323-34.

69 Chaput N, Louafi S, Bardier A, et al. Identification of

CD8+CD25+Foxp3+ suppressive T cells in colorectal cancer tissue. Gut 2009;58:520-9.
70 Chen C, Chen D, Zhang Y, et al. Changes of CD4+CD25+FOXP3+ and CD8+CD28- regulatory T cells in non-small cell lung cancer patients undergoing surgery. Int Immunopharmacol 2014;18:255-61.

71 Rabinovich GA, Toscano MA. Turning 'sweet' on immunity: galectinglycan interactions in immune tolerance and inflammation. Nat Rev Immunol 2009;9:338-52.

72 Compagno D, Gentilini LD, Jaworski FM, et al. Glycans and galectins in prostate cancer biology, angiogenesis and metastasis. Glycobiology 2014;24:899-906.

73 Fridman WH, Zitvogel L, Sautès-Fridman C, et al. The immune contexture in cancer prognosis and treatment. Nat Rev Clin Oncol 2017;14:717-34

74 Demotte N, Wieërs G, Van Der Smissen P, et al. A galectin-3 ligand corrects the impaired function of human CD4 and CD8 tumorinfiltrating lymphocytes and favors tumor rejection in mice. Cancer Res 2010;70:7476-88.

75 Farace F, Massard C, Vimond N, et al. A direct comparison of CellSearch and ISET for circulating tumour-cell detection in patients with metastatic carcinomas. Br J Cancer 2011;105:847-53. 